Araujo, Geraldo José Ferraresi de y Navarro, Luiz Felipe Scaranti. La importancia de las prácticas sustentables en las organizaciones deportivas: Estudio sobre el Proyecto Eco Aficionado. GeoGraphos [En línea]. Alicante: Grupo Interdisciplinario de Estudios Críticos y de América Latina (GIECRYAL) de la Universidad de Alicante, 2 de septiembre de 2015, vol. 6, $\mathrm{n}^{\mathrm{o}}$ 81, p. 202-235. [ISSN: 2173-1276] [DL: A 371-2013] [DOI: 10.14198/GEOGRA2015.6.81].

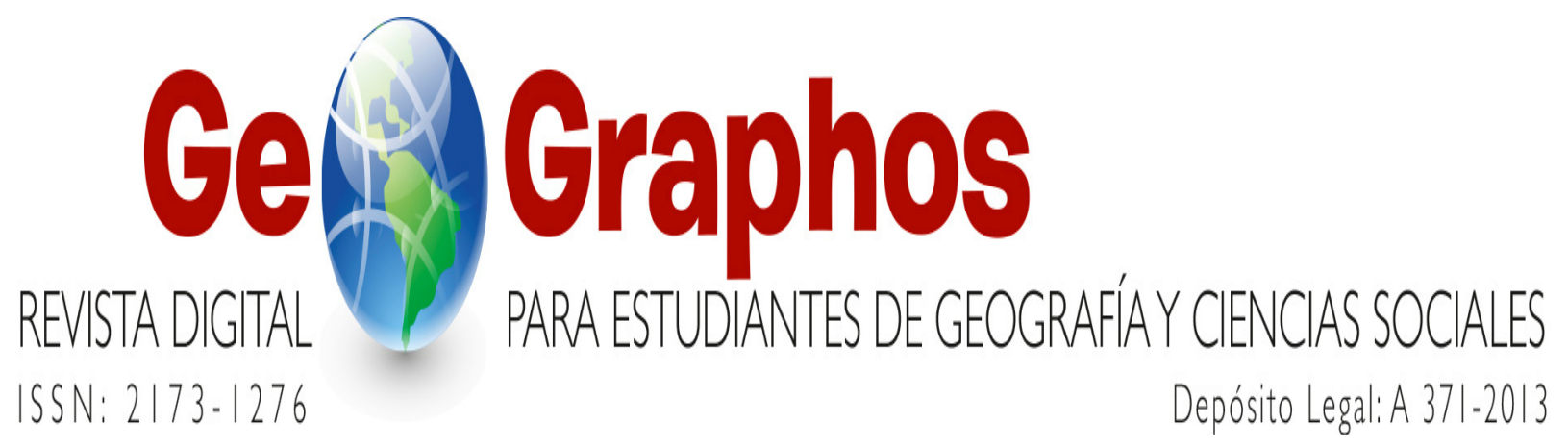

$<\underline{\text { http://web.ua.es/revista-geographos-giecryal }>}$

\title{
LA IMPORTANCIA DE LAS PRÁCTICAS SUSTENTABLES EN LAS ORGANIZACIONES DEPORTIVAS: ESTUDIO SOBRE EL PROYECTO ECO AFICIONADO
}

\author{
Geraldo José Ferraresi de Araujo \\ Graduado en Administración \\ Facultad de Economía, Administración y Contabilidad \\ Universidad de São Paulo (Ribeirão Preto, Brasil) \\ Correo electrónico: geraldoferraresi@gmail.com \\ Luiz Felipe Scaranti Navarro \\ Graduado en Administración \\ Facultad de Ciencias Agrarias y Veterinarias \\ Universidad Estadual Paulista "Julio de Mesquita Filho" (Jaboticabal, Brasil) \\ Correo electrónico: 1uizfsn@sp.sebrae.com.br
}

Recibido: 8 de diciembre de 2014. Devuelto para revisión: 20 de febrero de 2015.

Aceptado: 2 de septiembre de 2015 


\title{
RESUMEN
}

Con el agravamiento de las cuestiones ambientales, económicas y sociales en los años setenta, las Naciones Unidas iniciaron debates multilaterales, con el objetivo de repensar el desarrollo. El fútbol, con un público estimado en 250 millones de practicantes y con una industria evaluada en USD 500 billones, tiene participación estratégica en la construcción del desarrollo sustentable, como ejemplo se puede enfatizar el proyecto Eco Aficionado, aparcería realizada con los clubes de fútbol de São Paulo con la Federación Paulista de Fútbol, empresas, municipalidades y ONG's. Luego, el objetivo de este artículo es enfatizar el Eco Aficionado y encuadrarlo en el contexto histórico del desarrollo sustentable, sustentabilidad empresarial, su posicionamiento e importancia en la industria del fútbol, clasificarlo como una innovación tanto sustentable como de ruptura y presentar sus resultados. La metodología fue la investigación cualitativa, a través de la revisión bibliográfica. Durante la ejecución del proyecto, una tonelada de materiales reciclables fue colectada, plantadas 16.260 esquejes de árboles, colectadas 12.220 de ropas y juguetes, 3 mil toneladas de alimentos y 35 mil productos para la distribución. Sin embargo se puede señalar la relevancia del proyecto y la importancia del fútbol en la edificación de los principios sustentables en la sociedad, promoviendo el ejercicio de la ciudadanía, inclusión social, preservación ambiental y rentabilidad en la industria futbolística.

Palabras clave: Sustentabilidad, innovación, desarrollo sustentable, fútbol.

\section{THE IMPORTANCE OF SUSTAINABLE PRACTICES IN THE SPORT ORGANIZATIONS: THE STUDY ABOUT THE PROJECT ECO FAN}

\begin{abstract}
With the worsening of environmental, economic and social issues in the 1970s, the United Nations initiated multilateral discussions, aiming to rethink development. Football, with an audience estimated at 250 million practitioners and with an industry valued at USD 500 billion has participation in the construction of the sustainable development strategic, as an example you can cite the project Eco Fan, Partnership held by the football clubs of São Paulo with the Federação Paulista de Futebol, businesses, municipalities and NGOs. Soon, the goal of this article is to make a speech about the Eco fan and frame it in the historical context of sustainable development, business sustainability, its positioning and importance in the football industry, classify it as a sustainable innovation as disruptive and present their results. The methodology was qualitative research through the literature review. During the execution of the project, a ton of recyclables collected, planted 16. 260 seedlings of trees, collected 12. 220 of clothes and toys, 3 thousand tons of food and 35 thousand products for distribution. Therefore we can affirm the relevance of the project and the importance of football in building sustainable principles in society, promoting the exercise of citizenship, social inclusion, environmental conservation and income in the football industry.
\end{abstract}

Key Words: Sustainability, Innovation, Sustainable Development, Football. 


\section{A IMPORTÂNCIA DAS PRÁTICAS SUSTENTÁVEIS NAS ORGANIZAÇÕES ESPORTIVA: O ESTUDO SOBRE O PROJETO ECO TORCEDOR}

\section{RESUMO}

Com o agravamento das questões ambientais, econômicas e sociais nos anos setenta, as Nações Unidas iniciaram debates multilaterais, com o objetivo de repensar o desenvolvimento. $\mathrm{O}$ futebol, com um público estimado em 250 milhões de praticantes e com uma indústria avaliada em USD 500 bilhões, tem participação estratégica na construção do desenvolvimento sustentável, como exemplo pode se citar o projeto Eco Torcedor, parceria realizada junto aos clubes de futebol de São Paulo com a Federação Paulista de Futebol, empresas, prefeituras e ONG's. Logo, o objetivo deste artigo é dissertar sobre o Eco Torcedor e enquadrá-lo no contexto histórico do desenvolvimento sustentável, sustentabilidade empresarial, seu posicionamento e importância na indústria do futebol, classificá-lo como uma inovação tanto sustentável quanto disruptiva e apresentar seus resultados. A metodologia foi à pesquisa qualitativa, através da revisão bibliográfica. Durante a execução do projeto, uma tonelada de materiais recicláveis coletados, plantadas 16.260 mudas de arvores, coletadas 12.220 de roupas e brinquedos, 3 mil toneladas de alimentos e 35 mil produtos para a distribuição. Portanto pode-se afirmar a relevância do projeto e a importância do futebol na edificação dos princípios sustentáveis na sociedade, promovendo o exercício da cidadania, inclusão social, preservação ambiental e renda na indústria futebolística.

Palavras chave: Sustentabilidade, inovação, desenvolvimento sustentável, futebol.

\section{INTRODUCCIÓN}

Ante el agravamiento de las cuestiones sociales, ambientales y económicas tras treinta años de crecimiento económico de la posguerra, se inició una serie de debates internacionales sobre la necesidad de reforma del presente modelo de desarrollo, el capitalismo, basado en el crecimiento económico sin contemplar la preservación ambiental y la promoción social.

A través de los debates de la Primera Conferencia Mundial sobre el Hombre y el Medio Ambiente, realizada en Estocolmo - Suecia, en 1972, entre el desarrollo cero y el eco desarrollo, y las investigaciones realizadas por el Programa de las Naciones Unidas para el Medio Ambiente, a través de la Comisión Mundial sobre el Medio Ambiente y Desarrollo, a partir de 1982, liderada por la primera-ministra de Noruega Gro Harlem Brundtland, resultaron en la publicación del informe "Nuestro Futuro Común", también llamado de "Informe Brundtland", que define el concepto de desarrollo sustentable: "como aquel que atiende a las necesidades del presente sin comprometer la posibilidad de las generaciones futuras atender sus propias necesidades” (Brundtland, 1991, p. 46).

En ese sentido, estados, gobiernos, empresas, ONG's y organismos multilaterales tienen un papel importante en el proceso de ejecución del desarrollo sustentable. En lo que se refiere a las organizaciones deportivas ligadas al fútbol, de acuerdo con la consultoría Deloitte Touche Tohmatsu Límited (2012) esa industria mueve cerca de 500 billones de dólares anualmente, lo que demuestra el potencial de esa industria en contribuir de manera superlativa para la edificación y consolidación de las prácticas sustentables tanto en Brasil como en cualquier parte del mundo.

Como ejemplo al expuesto, se puede enseñar el proyecto Eco Aficionado, que es una aparcería realizada junto a los clubes de fútbol de primera división del estado de São Paulo con la Federación Paulista de Fútbol. Las acciones realizadas por el programa fueron: plantío de bosques urbanos, 
colecta de residuos sólidos reciclables, donaciones sociales, selección sustentable, escuela sustentable y Ecopa. Como resultado del proyecto en el Campeonato Paulista Serie A1, de 2013, más de una tonelada de residuos reciclables fueron colectados en los eco puntos instalados en los estadios, plantados 16.260 esquejes para la formación de bosques urbanos, fueron recaudados 12.220 ítems en ropas y juguetes y tres toneladas de alimentos no perecederos además de 35 mil ítems de higiene y limpieza para las ONG's.

Sin embargo, dado a su carácter relevante para el desarrollo sustentable, para la construcción de sociedades sustentables, posibilidad de su aplicación en los grandes eventos deportivos nacionales e internacionales, como también en otras modalidades deportivas, se justifica su investigación a través de este artículo.

Así el objetivo de esta investigación es disertar de manera descriptiva y exploratoria, posteriormente sometido a análisis de contenido, el Proyecto Eco Aficionado ejecutado en la Serie A1 del Campeonato Paulista de 2013 de 19 de enero a 19 de mayo y encuadrarlo en el contexto histórico del desarrollo sustentable, sustentabilidad empresarial, su posicionamiento e importancia en la industria del fútbol, clasificarlo como una innovación tanto sustentable como de ruptura de nuevo mercado y presentar sus resultados obtenidos, por donde también el tema de la investigación está delimitado.

Para lograr éxito en la investigación, fue realizado un levantamiento bibliográfico en las bases; datos de la Scientific Electronic Library Online; Programa de las Naciones Unidas para el Medio Ambiente; Sistema Integrado de Bibliotecas de la Universidad Estadual Paulista, Universidad de São Paulo y de la Universidade Estadual de Campinas; Instituto Ethos y Federación Paulista de Fútbol.

Esas fuentes tuvieron acceso entre los meses de enero y noviembre de $2014 \mathrm{y}$, en esas bases de datos fueron cruzadas las siguientes palabras-clave: desarrollo sustentable, sustentabilidad organizacional, deporte, fútbol y proyecto Eco Aficionado, posteriormente, fueron evaluados y seleccionados los artículos más relevantes.

\section{EDIFICACIÓN HISTÓRICA DEL CONCEPTO DE DESARROLLO SUSTENTABLE}

Analizar la construcción y emergencia del concepto de desarrollo sustentable es comprender los procesos que culminaron en la edificación de la consciencia del agotamiento del presente modelo de desarrollo, experimentado en los últimos tres siglos, marcados por las premisas de la libre iniciativa, de la lógica de acumulación de riqueza y por las revoluciones científicas tecnológicas que culminaron con la emergencia y en el desarrollo de productos, servicios y procesos que ampliaron considerablemente la capacidad de producción, proporcionando grande avance económico, pero como consecuencia: concentración de riquezas, desigualdades sociales, desempleo estructural y perjuicios ambientales.

Esos factores hicieron surgir diversas corrientes de pensamientos, estudios e investigaciones, con el objetivo de elaborar un modelo que permita aliar estas formas de desarrollo con la mejora de la interacción humana con el medio ambiente y la preservación del mismo.

Para G. Lima (1997) la multiplicación de los problemas ambientales y la acción de los movimientos ecológicos, sobre todo a partir de la década de 1970, componen una fuerza crítica al modelo de 
desarrollo industrial y despiertan una nueva consciencia, atenta a la dimensión ambiental y social de la realidad.

El desarrollo sustentable asumió, por tanto, al final del siglo XX, un papel importante en la reflexión acerca del modelo de desarrollo económico vigente y sus impactos sociales y ambientales tanto en escala regional como global y surgió para enfrentar la crisis ecológica que se presentaba, sobre todo en el posguerra caracterizado por E. Hobsbawn (1995) por un rápido crecimiento económico que tuvo como consecuencia considerable la degradación ambiental y la exclusión social. Para P. Jacobi (2006) dos corrientes de pensamiento emergieron para elaboración y debate de nuevas propuestas de desarrollo.

El Club de Roma, creado en 1968, organización formada por científicos, políticos y empresarios, cuyo objetivo era discutir asuntos relacionados a la política, economía, medio ambiente y desarrollo sustentable, encomendó junto al Masachusetts Institute of Technology el informe intitulado "Los Límites del Crecimiento", también conocido como Informe del Club de Roma o Informe Meadows.

De acuerdo con C. Cavalcanti (1995) este informe, liderado por los investigadores Donella H. Meadows, Dennis L. Meadows, Jorgen Randers y William W. Behrens III se basaba en una serie de modelos matemáticos para prever la relación entre el crecimiento de la población mundial, la industrialización, la producción de alimentos y la disminución de los recursos naturales. Se concluyó que, caso las formas de producción continuaran en el ritmo presentado en el momento del estudio, los límites de crecimiento serían alcanzados en un plazo de 100 años.

Alertaba, por tanto para el hecho de que la humanidad tendría, obligatoriamente, un límite de crecimiento con el modelo económico entonces practicado, basado en el consumo y concentrado en pocas naciones. Como propuesta, el Informe Meadows presenta como necesario el congelamiento del crecimiento de la población global y del capital industrial, mostrando la limitación de los recursos naturales (Instituto Brasileño de Medio Ambiente y de los Recursos Naturales Renovables, 2009).

Pero, la primera iniciativa global en el ámbito del desarrollo sustentable fue la realización de la Conferencia Internacional para el Medio Ambiente Humano, promocionada por las Naciones Unidas en Estocolmo - Suecia, también en 1972, (UN Conference on the Human Environment) un marco histórico-político decisivo para el surgimiento de políticas de gerenciamiento ambiental, direccionando la atención de las naciones para las cuestiones ambientales (Passos, 2009).

La Conferencia de Estocolmo reflejó la preocupación con la vulnerabilidad de los ecosistemas naturales. Su énfasis estaba en los aspectos técnicos de la contaminación provocada por la industrialización acelerada, por la explosión demográfica y por la expansión del crecimiento urbano (Guimarães, 1991).

Se puede señalar que el tono predominante fue la polémica entre países desarrollados y subdesarrollados. A pesar de los conflictos, la Conferencia hubo repercusión mundial, desencadenando la creación del Programa de las Naciones Unidas para el Medio Ambiente (PNUNA), aprobación de 25 principios fundamentales que orientan las acciones internacionales en el área ambiental y la mayor comprensión de la urgencia de adoptarse un nuevo posicionamiento ante las cuestiones ambientales. 
Fue, por lo tanto, en el contexto del Informe Meadows y de la Conferencia de Estocolmo, que surgió una propuesta de un nuevo modelo de desarrollo, que debería necesariamente contemplar la preservación ambiental y a la vez permitir el crecimiento económico de las naciones.

En 1973, Maurice Strong propuso un modelo de desarrollo con bases ambientales, también conocido como Eco Desarrollo. Ignacy Sachs formuló los principios de esa nueva visón de desarrollo, donde son adjuntas seis directrices que las políticas de desarrollo de los países deberían seguir. Son ellas:

[...] a) la satisfacción de las necesidades básicas; b) la solidaridad con las futuras generaciones; c) la participación de la población involucrada; d) la preservación de los recursos naturales y del medio ambiente en general; e) elaboración de un sistema social, y f) programas de educación (Brüseke, 1995, p. 31).

La idea del Eco Desarrollo fue la base para la emergencia del concepto de desarrollo sustentable, en la medida en que se propone la integración garantizando empleo, seguridad social y sobre otras culturas entre desarrollo, medio ambiente y comunidades, considerando los límites de renovación de los recursos naturales (Sachs, 1986).

El término "desarrollo sustentable" fue discutido por primera vez en el documento World's Conservation Strategy (International Union for Conservation of Nature and Natural Resources, United Nations Environment Programme y World Wildlife Fund, 1980) elaborado por la International Union for the Conservation of Nature and Natural Resources (IUCN). Centrado en la cuestión de la integridad ambiental. Este documento pone en relieve la importancia de las dimensiones social, ecológica y económica para el alcance de la sustentabilidad, considerándose los recursos vivos y no vivos y las ventajas de corto y largo plazo de acciones alternativas.

En 1982, diez años tras la Conferencia de Estocolmo, bajo supervisión del PNUNA, en Nairobi Quenia, fue decidido la formación de una Comisión Mundial de Medio Ambiente y Desarrollo (CMMAD), implementada en 1983 por la Asamblea General de las Naciones Unidas, que tuvo como líder la primera-ministra de Noruega Gro Harlem Brundtland. La comisión tenía como objetivo reexaminar los principales problemas del medio ambiente y del desarrollo, en ámbito mundial, y formular propuestas realistas para solucionarlos.

En abril de 1987, el CMMAD se presentó el informe Our Common Future también conocido como Informe Brundtland. El informe, con 430 páginas, trae una nueva perspectiva para el desarrollo. Estructurado en 3 partes: I.- preocupaciones comunes; II.- desafíos comunes y III.- esfuerzos comunes. El Informe parte de una visión compleja de las causas de los problemas socioeconómicos y ecológicos de la sociedad global que deben ser alteradas para que se pueda alcanzar el desarrollo sustentable y, ello parte del principio de la posibilidad y de la necesidad de conciliar crecimiento económico y conservación ambiental. Llama también atención para una nueva postura ética, caracterizada por la responsabilidad tanto entre las generaciones como entre los miembros contemporáneos de la sociedad actual (Mota et al., 2008).

La definición de desarrollo sustentable, de acuerdo con el Informe Brundtland (1991, p.10)

[...] El desarrollo que procura satisfacer las necesidades de la generación actual, sin comprometer la capacidad de las generaciones futuras de satisfacer sus propias necesidades, significa posibilitar que las personas, ahora y en el futuro, atinjan un nivel satisfactorio de desarrollo social y económico y de realización humana y cultural, haciendo, a la vez, un uso razonable de los recursos de la tierra y preservando las especies y los hábitats naturales. 
El informe Brundtland no trató únicamente de los problemas ambientales, sino que lo hizo por una perspectiva sistémica entre los modelos de desarrollo y sus respectivos impactos sobre la naturaleza. La sustentabilidad del desarrollo y de la necesidad de tratarlo de una perspectiva multidimensional articuló los aspectos económicos, políticos, éticos, sociales, culturales y ecológicos. Presenta una filosofía de desarrollo que combina eficiencia económica con preservaciones ambientales y justicia social. Los problemas ambientales y del desarrollo sustentable se encuentran relacionados a la pobreza, que puede ser considerado como un problema ambiental y como un tópico fundamental para la búsqueda de la sustentabilidad, siendo necesario, por lo tanto, la satisfacción de las necesidades básicas de alimentación, salud y vivienda de la población (Guimarães, 1991).

A. Dahl (1997) aunque señala que la definición de desarrollo sustentable por el Informe Brundtland es genérico, no quedando clara la responsabilidad a respecto de las dimensiones del desarrollo sustentable. F. Brüseke (1995), señala que ella apunta el concepto en la dirección correcta. Una perspectiva multidimensional, que abarca economía, ecología y política $\mathrm{y}$, a la vez, es contrapunto fundamental a la idea ultrapasada de modernización tardía que beneficia algunos sectores de la economía, mas que es incapaz de ofrecer un modelo de desarrollo equilibrado a la sociedad como un todo.

Tras la publicaciones del Informe Our Common Future, la Asamblea General de las Naciones Unidas decidió realizar la Conferencia de las Naciones Unidas sobre Medio Ambiente y Desarrollo en Rio de Janeiro, en 1992, donde el desarrollo sustentable pasó a ser la cuestión principal de política ambiental. Esa Conferencia, también conocida como Cúpula de la Tierra, Conferencia de Rio, Eco 92 o Rio 92 que reunió 108 jefes de estado y de gobierno, 172 delegaciones de países, 10 mil periodistas y 1.400 representantes de organizaciones no gubernamentales para buscar mecanismos que rompiesen con el abismo de desarrollo entre países ricos y pobres y también preservar el medio ambiente (Lago, 2006).

Entre los acuerdos internacionales advenidos de ese encuentro fueron: Declaración de Principios sobre Florestas; Convención sobre Diversidad Biológica; Convención Cuadro sobre Cambios Climáticos; Convención del Clima, Agenda 21; Convención de la Biodiversidad; Declaraciones de Rio de Janeiro; programa de acción global con 40 capítulos y un conjunto de 27 principios por medio de los cuales debería ser conducida la interacción de los seres humanos con el planeta. Esos acuerdos dieron margen a las reglamentaciones. En relación a esos temas por parte de las agencias ambientales de varios países.

Tales documentos, específicamente la Agenda 21 y la Declaración de Rio, definieron el contorno de políticas públicas para alcanzar el desarrollo sustentable que atendiese a las necesidades de los más pobres y reconociese los límites de ese desarrollo en escala internacional. El término "necesidades" debería ser interpretado bajo la óptica económica, pero también so la forma de creación de un sistema que privilegiase tanto la dimensión ambiental como la social.

En 1997, hubo el primer ciclo de evaluación de los resultados de la Conferencia Rio 92, cuando la Sesión Especial de la Asamblea General de las Naciones Unidas, conocida como Rio+5, realizó tres eventos en aquel año para revisar la implementación de la Agenda 21:

1. El Fórum Rio+5, el mes de marzo, en Rio de Janeiro, donde Organizaciones No Gubernamentales debatieron acciones efectivas sobre el desarrollo sustentable; 
2. La $5^{\text {a }}$ sesión de la Comisión sobre Desarrollo Sustentable (CDS) de la ONU, en abril, en Nueva York, negoció los documentos para que fueran aprobados en el encuentro de la Asamblea General de la ONU;

3. Sesión Especial de la Asamblea General de la ONU, en junio, en Nueva York.

A través de esos tres encuentros una serie de huecos fueron identificados, específicamente a lo que se refiere a las dificultades para alcanzar la igualdad social y reducir los niveles de pobreza. Se trataba de una situación común a muchos países en desarrollo, provocada por: la reducción de los auxilios financieros internacionales, la posición en la división internacional de trabajo, la corrupción, por el crecimiento de las deudas externas y por el fracaso en el proceso de transferencia de tecnología y coordinación institucional.

El documento final del evento Fórum Rio+5 de las Naciones Unidas fue una "Declaración de Compromiso", en la cual fueron ratificados los acuerdos de la Rio-92, garantizando la continuidad de la implementación de las determinaciones y de mayor eficiencia en la implementación del creciente número de convenciones y acuerdos internacionales referentes al medio ambiente $\mathrm{y}$ desarrollo (Cordani; Marcovitch; Salati, 1997).

A partir de ello, la Comisión de Desarrollo Sustentable de la ONU (CDS) dio como sugerencia la realización, el año de 2002, de una nueva Cúpula Mundial, de esta vez sobre Desarrollo Sustentable - La Cimera de la Tierra, en Johannesburgo - África del Sur.

La Conferencia de las Naciones Unidas sobre Ambiente y Desarrollo Sustentable, la Rio +10 , reunió 100 jefes de estado y gobierno, 189 representantes de países y 15 mil representantes de la sociedad civil. Con el objetivo de revisar las metas propuestas por la Agenda 21 y direccionar las realizaciones a las áreas que requieren un esfuerzo más grande para su implementación, como también evaluar sobre otros acuerdos y tratados de la Rio 92.

La Rio + 10 llevaría a la definición de un plan de acción internacional, capaz de conciliar las necesidades legítimas de desarrollo económico y social de la humanidad, con la obligación de mantener el planeta habitable para las generaciones futuras. Además, en realidad, lo que se logró como resultado fue un plan de acción o de implementaciones, no vinculante, de 153 párrafos, sin vigilia o sanción y una Declaración Política sin el peso y la legitimidad de la Declaración de Rio.

La Declaración de Johannesburgo reafirmó los compromisos firmados en la Eco 92 y también adjuntó los desafíos que fueron y están siendo enfrentados por las naciones participantes del encuentro, como: la reafirmación del compromiso con el desarrollo sustentable, la importancia del multilateralismo democrático responsable y con ello asumieron el compromiso de trabajar en conjunto para la concretización de los objetivos propuestos (Comité de Calidad de la Gestión Pública, 2002).

Para Mikhailova (2004) el concepto actual de desarrollo sustentable, que fue expreso en la Cúpula Mundial en 2002, abarca la definición más concreta del objetivo de desarrollo actual (la mejoría de la calidad de vida de todos los habitantes) y, a la vez distingue el factor que limita tal desarrollo pudiendo perjudicar las generaciones futuras, el uso de recursos naturales, además de la capacidad del planeta. La integración de acción es necesaria en tres áreas-clave:

- Crecimiento y Equidad Económica: Los sistemas económicos globales interrelacionados demandan un abordaje sistémico para promocionar un crecimiento responsable; 
- Conservaciones de Recursos Naturales y del Medio Ambiente: soluciones deben ser desarrolladas con el objetivo de reducir el consumo de recursos, detener la polución y conservar los hábitats naturales;

- Desarrollo Social: Se debe asegurar que la diversidad cultural y social sean respetadas, y todos los miembros de la sociedad estén capacitados a participar en la determinación de sus futuros.

Estas tres dimensiones están basadas en el concepto de Triple Botton Line. Analizándolos separadamente, se tiene: Económico, cuyo propósito es la realización de emprendimientos rentables; Ambiental, cuyo objetivo es analizar la interacción de procesos con el medio ambiente sin causarle daños permanentes; y Social, que se preocupa con el establecimiento de acción justas para trabajadores, aparceros y sociedad. Juntos, estos tres pilares se relacionan de tal forma que la intersección entre dos pilares resulta en viable, justo y habitable, y de los tres, resultaría en el alcance de la sustentabilidad, según se muestra en la figura 1.

El desarrollo sustentable pasa entonces a tener una connotación política que trasciende a su propia capacidad de transformación de los patrones de producción y consumo actuales, mismo que su discusión avance hacia el entendimiento de su esencia como proceso que mejore las condiciones de vida de las comunidades humanas y, a la vez, respete los límites y la capacidad de carga de los ecosistemas. Esta visión de mundo, pos iluminista, que amplía para además de las degradaciones del ambiente físico y biológico, las variables consideradas en el contexto del desarrollo sustentable, como la pobreza y la exclusión social, e incorpora las dimensiones sociales, políticas y culturales al proceso, evoca una nueva postura de relacionamiento hombre/sociedad/naturaleza (Sachs, 1986, 1993; Barbieri, 1997) que resulte en personas viviendo con derecho a la justicia e igualdad de tratamiento, eliminaciones o reducción de la degeneración ambiental sin que las acciones actuales inviabilice la continuidad de la supervivencia en el planeta (Kelly; Moles, 2000; Rattner; Veiga, 2002).

\section{SUSTENTABILIDAD EMPRESARIAL}

Del mismo modo, tras cuarenta años de discusiones internacionales sobre los impactos sociales, económicos y ambientales del presente modelo de desarrollo, de la elaboración tanto del concepto de desarrollo sustentable como importancia para el Informe Brundtland, de acuerdo con la Conferencia de las Naciones Unidas sobre el Desarrollo Sustentable (2012) dos tercios de los servicios que la naturaleza ofrece para la humanidad están en baja; las emisiones globales anuales de dióxido de carbono crecieron 38\% entre 1990 y 2009; 20\% de la población internacional no tiene acceso a la electricidad. La pobreza aún mantiene 57 millones de niños en todo el mundo fuera de la escuela y cerca de $16 \%$ de los adultos, cerca de 793 millones de personas, carecen de habilidades básicas de alfabetización y pérdida anual de cerca de 5,2 millones de hectáreas de cobertura forestal. 


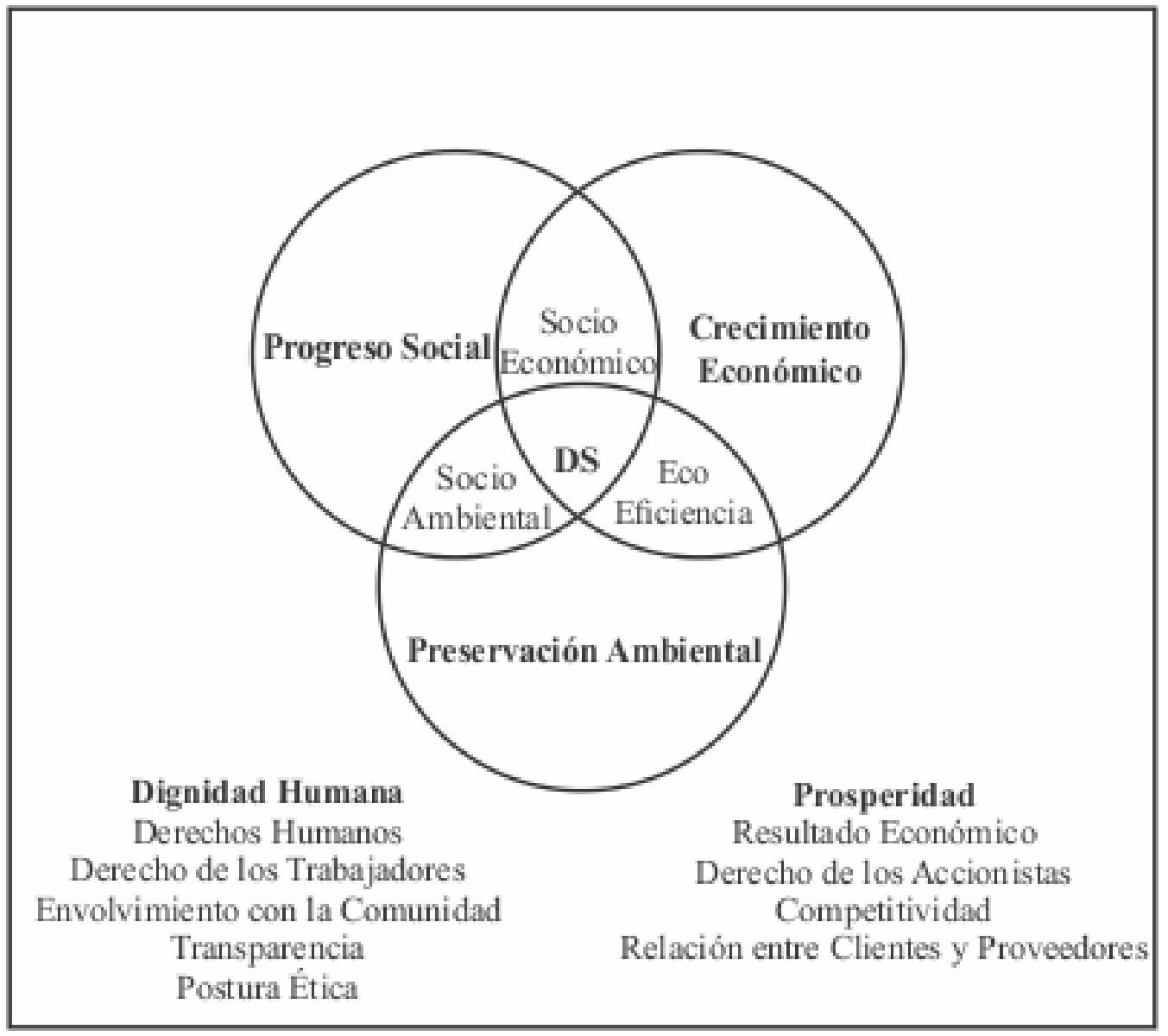

Fuente: $\operatorname{Kraemer}^{1}$ (2003, apud Araujo, 2006, p. 83).

La ejecución de las decisiones tomadas en las conferencias de las Naciones Unidas sobre el Medio Ambiente y el Desarrollo Sustentable tiene como mayores responsables tanto las naciones signatarias de los acuerdos firmados como las empresas, en la medida en que esas organizaciones tienen un papel central en el presente modo de producción, el capitalismo.

Pensadores económicos modernos creen que las empresas, además de contemplar los resultados financieros, tienen la función ética de respetar las leyes, promocionar el bienestar y el interés de los colaboradores, los clientes, los proveedores, los funcionarios, los accionistas, la comunidad local y también preservar el medio ambiente, o sea, implementar metodologías de gestión que vayan hacia los principios del desarrollo sustentable.

Para E. Coral (2002), además de los factores económicos y estructurales, otros comienzan a formar parte de la responsabilidad de las empresas, las cuestiones sociales y ambientales. Para que las organizaciones puedan contribuir con el desarrollo sustentable deben modificar sus procesos productivos, cuando sea necesario, para que se vuelvan ecológicamente sustentables. Ello implica en construir sistemas de producción que no causen impactos negativos y que estén contribuyendo

\footnotetext{
${ }^{1}$ ARAUJO, G. C. El proceso de implantación de la sustentabilidad en frigoríficos: estudio de caso en el Frigorifico Independencia. Disertación de Maestría en Agronegocio. Campo Grande: Universidad Federal de Mato Grosso do Sul, 2006.
} 
para la recuperación de áreas degradadas u ofreciendo productos y servicios que contribuyan para la mejora de la performance ambiental de los consumidores y clientes de una industria.

De acuerdo con el Busines for Social Responsibility, no existe una definición única para sustentabilidad empresarial, también conocida como responsabilidad social corporativa, se refiere a decisiones de negocios tomadas con base en valores éticos que incorporen las dimensiones legales, el respeto por las personas, por las comunidades y por el medio ambiente (Machado Filho y Zylbersztajn, 2004).

Para el Cuadro Europeo para la Responsabilidad Social de las Empresas, el Libro Verde, la responsabilidad social de las empresas es definida como la integración voluntaria de preocupaciones sociales y ambientales, por parte de las empresas, en sus operaciones y en su interacción con las otras partes interesadas. También es definida, en un sentido más amplio, como un concepto en el que las empresas deciden, en una base voluntaria, contribuir para una sociedad más justa y para un ambiente más limpio (Unión Europea, 2001).

Luego, la práctica de la sustentabilidad empresarial es de fundamental importancia para la creación y consecuente sustentación de ventaja competitiva, pues consigue obtener la preferencia de los consumidores, de acuerdo con M. Porter (1985, p. 3),

\footnotetext{
Ventaja competitiva surge, fundamentalmente, del valor que una empresa es capaz de crear para sus compradores, valor este que excede el costo de la empresa en crearlo. Valor es lo que los compradores están dispuestos a pagar, y valor superior proviene de la oferta de precios inferiores a los de los concurrentes para beneficios equivalentes o el fornecimiento de beneficios únicos que compensan un precio superior.
}

M. Porter y C. Van Der Linde (1995) vislumbran sinergias entre ventaja competitiva y preservación del medio ambiente. Argumentan que la imposición de patrones ambientales adecuados puede estimular a las empresas a adoptaren innovaciones que reducen los costos totales de un producto o aumentan su valor, mejorando su competitividad. Es decir, además de las mejoras ambientales, las reglamentaciones ambientales también reforzarían las condiciones de competitividad empresarial (Young; Lustosa, 2001). Estas innovaciones pueden eliminar desperdicios o viabilizar económicamente un subproducto considerado rechazo industrial, aumentando así la productividad y reduciendo costos. De esta forma, la hipótesis de Porter propone que, en una perspectiva dinámica y a largo plazo, las medidas comerciales con finalidad de preservación ambiental pueden aumentar la competitividad de las empresas.

B. Husted y D. Allen (2001) corroboran con argumentos fundamentados de M. Porter y C. Van Der Linde (1995), para aquellos autores, la definición de estrategia social corporativa abarca la cuestión de la ventaja competitiva: es el posicionamiento de la organización con respecto a temas sociales de forma a alcanzar objetivos sociales a largo plazo y crear ventaja competitiva.

Los objetivos sociales se refieren a todas las metas no directamente relacionadas con la creación del valor añadido al cliente o la maximización de la riqueza del accionista. Están estrechamente relacionados con la noción de performance social corporativa, tratándose de la satisfacción de las expectativas de los stakeholders.

El posicionamiento de la empresa permite alcanzar objetivos sociales al reducir la distancia entre la empresa y sus stakeholders, habiendo así un impacto positivo en la performance social corporativa. Además, "la estrategia social debe crear ventaja competitiva al desarrollar capacidades únicas que tengan un impacto positivo en el lucro de la empresa" (Husted; Allen, 2001, p. 37). 
Para la edificación de procesos sustentables en la gestión empresarial que puedan servir de base para la edificación y consolidación de ventaja competitiva, la utilización de indicadores de sustentabilidad que son una herramienta esencial para garantizar la transparencia y manifestar el compromiso de las organizaciones acerca de la responsabilidad social y preservaciones ambientales.

Estos indicadores tienen la función de facilitar la presentación de información sobre los impactos causados por la organización de forma a propiciar la comparación entre informes y organizaciones, además de permitir acompañar el alcance de las metas, identificar avances y corregir problemas.

Siendo así, de acuerdo con J. Strobel (2005) para que un indicador atienda a su objetivo, debe ser transparente, completo, relevante, preciso, neutro, comparable y audible.

El cuadro a seguir sintetiza los principales indicadores económicos, sociales y ambientales de la sustentabilidad empresarial.

Cuadro 1. Principales indicadores de la sustentabilidad empresarial

\begin{tabular}{|c|c|c|}
\hline Indicadores Ambientales & Indicadores Económicos & Indicadores Sociales \\
\hline $\begin{array}{l}\text { - Agua; } \\
\text { - Atendimento a las } \\
\text { legislaciones; } \\
\text { - Energía; } \\
\text { - } \text { Biodiversidad; } \\
\text { - Impactos ambientales; } \\
\text { - Productos ecológicamente } \\
\text { correctos; } \\
\text { - Reciclaje; } \\
\text { - Tecnologías limpias; } \\
\text { - Tratamiento de afluentes. }\end{array}$ & $\begin{array}{l}\text { - Costo; } \\
\text { - Exportaciones; } \\
\text { - Estrategias de negocios; } \\
\text { - Lucro; } \\
\text { - Hoja de pago; } \\
\text { - Inversión; } \\
\text { - Lucro; } \\
\text { - Mercado; } \\
\text { - Calidad; } \\
\text { - Receta; } \\
\text { - Ventaja competitiva. }\end{array}$ & 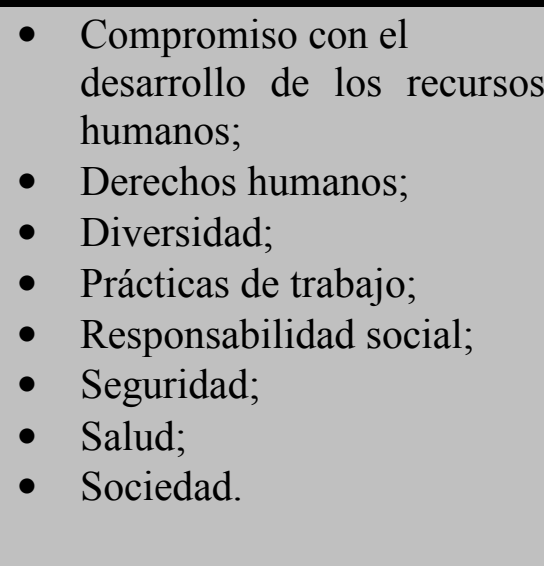 \\
\hline
\end{tabular}

Fuente: G. Araújo, W. Moraes y P. Mendonça (2006).

A través del análisis de los indicadores de sustentabilidad, las empresas pueden "medir" su nivel de sustentabilidad, posibilitando así desarrollar las mejores prácticas en la búsqueda del desarrollo sustentable y consecuentemente crear valor a todos sus stakeholders.

\section{INNOVACIÓN}

La exigencia de organizaciones empresariales más competitivas es una realidad cada vez mayor con la profundización de la globalización y con la revolución en los medios de transporte y comunicación. Ante ese escenario se hizo necesario que las empresas se adaptasen a la concurrencia global, buscando el desarrollo de modo a garantizar su supervivencia y liderazgo en el mercado. Ante el presente escenario, la innovación es mantenida como un factor clave en la definición de mejores niveles de productividad, calidad, precio y flexibilidad por parte de la organización.

J. Schunpeter ${ }^{2}$ (2004 apud Sbaraini, 2013, p. 19), uno de los primeros autores a desarrollar el concepto de innovación, lo define así:

\footnotetext{
${ }^{2}$ SCHUMPETER, J. A. The Theory of Economic Development. New Jersey: Brunswick, 2004. p. 19.
} 
a) Introducción de un nuevo bien, cuyos consumidores aún no estén familiarizados, introducción de un nuevo método de producción, y que haya sido generado a partir de una nueva descubierta científica, o un nuevo método de tratar comercialmente commodity; b) Apertura de un nuevo mercado, en que una área específica de la industria, aún no haya penetrado, independientemente del mercado que ya existe; c) La conquista de una nueva fuente de abastecimiento de materia prima, parcialmente manufacturados; d) El aparecimiento de una nueva estructura organizacional en un sector.

De acuerdo con la Ley 10.973, conocida como la Ley del Bien (Brasil, 2004) en su artículo según define innovación como "introducción de novedad o perfeccionamiento en el ambiente productivo o social que resulten nuevos productos, procesos o servicios."

Para el Manual de Oslo, innovación es la implementación de un producto (bien o servicio) nuevo o significativamente mejorado, o un proceso, o un nuevo método de marketing, o un nuevo método organizacional en las prácticas de negocios, en la organización del local de trabajo o en las relaciones externas (Organisation for Economic Cooperation and Debleopment, 1997).

En lo que se refiere a los tipos de innovación, de acuerdo con el Manual de Oslo, se tiene una de las definiciones más bien aceptas, según el cuadro 2:

\section{Cuadro 2. Definiciones de los tipos de innovación}

\begin{tabular}{|l|l|}
\hline Innovación de producto & $\begin{array}{l}\text { Introducción de un bien o servicio nuevo o significativamente } \\
\text { mejorado en lo que se concierne sus características o usos } \\
\text { previstos. }\end{array}$ \\
\hline Innovación de proceso & $\begin{array}{l}\text { Es la implementación de un método de producción o distribución } \\
\text { nuevo o significativamente mejorado. }\end{array}$ \\
\hline $\begin{array}{l}\text { Innovación de } \\
\text { marketing }\end{array}$ & $\begin{array}{l}\text { Es la implementación de un nuevo método de marketing con } \\
\text { mudanzas significativas en la concepción del producto o en su } \\
\text { embalaje, en el posicionamiento del producto, en su promoción o } \\
\text { en la fijación de precios. }\end{array}$ \\
\hline $\begin{array}{l}\text { Innovación } \\
\text { organizacional }\end{array}$ & $\begin{array}{l}\text { Es la implementación de un nuevo método organizacional en las } \\
\text { prácticas de negocios de la empresa, en la organización de su } \\
\text { local de trabajo o en sus relaciones internas. }\end{array}$ \\
\hline
\end{tabular}

Fuente: OCDE (1997).

Las definiciones de innovación dichas anteriormente y sus respectivos tipos presentan los ciclos de mudanza de los negocios que va desde el lanzamiento hasta el crecimiento rápido. Al adentrar en la fase de madurez, pueden obtener algún crecimiento incremental, sin embargo, el riesgo de baja es alto. En ese sentido la innovación de ruptura iniciaría una nueva curva de crecimiento.

La expresión "Innovación Disruptiva" fue introducida por C. Christensen (1997), en su libro "El Dilema de la Innovación". El autor define innovación disruptiva como innovación que permite la entrada de nuevos participantes en el mercado, a partir de soluciones relativamente sencillas, convenientes y baratas que las existentes, siendo ofrecidas a los clientes menos exigentes de la base de la pirámide de mercado, o aún, a nuevos clientes y nuevos contextos de consumo. La ruptura ocurre cuando la innovación altera significativamente los modelos de negocio posibilitando atender segmentos no atendidos anteriormente, en una escala que altera la generación y la captura de valor por la empresa (Christensen; Raynor, 2003). 
Todavía para C. Christensen y M. Raynor (2003) diferencian las innovaciones disruptivas según su foco: innovaciones disruptivas de nuevo mercado y de bajo mercado. Las innovaciones disruptivas de nuevo mercado se refieren a innovaciones orientadas a clientes no-consumidores que no tiene acceso a determinados productos y servicios. (Zucatto; Pinhero, 2008). Las innovaciones disruptivas de bajo mercado se refiere a aquellas innovaciones introducidas en situación en que consumidores de un producto o servicio no utilizan (y no valoran) todos los atributos (por veces recursos que exigen tecnologías sofisticadas y caras) incorporados a ellos por las empresas ofertantes y líderes.

Para el Servicio Brasilero de Apoyo a la Micro y Pequeña Empresa (2007) cualquier tipo de innovación debe forzosamente traer ganancias para la empresa, como aumento de las ventas, rentabilidad, reducción de costos, aumento del portfolio de productos, diversificación de mercado y más competitividad.

La competitividad de un negocio, basada y la innovación, es hoy necesaria, señalan C. Prahalad y V. Ramaswamy (2003). No limitándose solamente a cuestiones como reducción de costo, mejor administración, control más restricto, mejor organización, reingeniería o tercerización, pero esencialmente crear valor de manera percibida y que haga creer el consumidor. Ese es el camino de la innovación, que así concebida, afecta el negocio en todas sus formas y actividades y el único camino para que las empresas consigan crecimiento.

Ante ese escenario, la innovación es una herramienta fundamental para edificación sustentación de ventaja competitiva, J. Tidd, J. Besant y K. Pavitt (2008), por su vez, formula que conceptualmente no es difícil establecer la relación entre la innovación y la competitividad, y por consiguiente, el desempeño de las empresas. La forma como la innovación afecta la posición competitiva de una empresa varía de acuerdo con la profundidad de la innovación, permitiendo a la empresa innovadora desde la simple creación de una nueva relación costo-beneficio para su producto o servicio hasta el establecimiento de un nuevo patrón de competición que cambie el modelo vigente antes de la innovación.

\section{Innovación sustentable}

El concepto de innovación elaborado por J. Schunpeter (1988), gana una nueva dimensión cuando analizado juntamente con la sustentabilidad. El proceso innovador necesita un enfoque sistémico para adecuarse y atingir excelencia en el desempeño económico, pero también, ambiental y social. La innovación tiene la oportunidad de contemplar ampliamente la noción de desarrollo sustentable, que puede ser efectuada bajo la óptica del triple bottom line, según presentado en la figura 1. Llevando en cuenta los ejes económico, social y ambiental de la sustentabilidad, se puede establecer una relación sistémica entre las dimensiones de la innovación.

Ya es posible encontrar en la bibliografía, autores que buscan conceptuar innovación sustentable. La relación entre innovación y la sustentabilidad ha ganado relevancia a partir del debate académico entre diversos autores.

Según las definiciones del IXL Center (Instituto de Investigación y Fomento a la Innovación, con sede en los EUA), las innovaciones sustentables son aquellas que crean y añaden valor sin comprometer el atendimiento a las necesidades de las generaciones futuras. 
La innovación sustentable es introducción de productos, procesos productivos, métodos de gestión o negocios, nuevos o significativamente mejorados para organización y que trae beneficios económicos, sociales y ambientales, comparados con alternativas pertinentes. Note que no se trata solo de reducir impactos negativos, pero de avanzar en beneficios líquidos, donde los beneficios esperados deben ser significativos o no negligentes en las tres dimensiones de la sustentabilidad.

Para M. Porter y C. Van Der Linde (1995), patrones ambientales adecuadamente desarrollados pueden catalizar innovaciones, disminuyendo costos y añadiendo valores, permitiendo, por tanto, uso más eficiente de los recursos. Por ello, según los autores, esta productividad de recursos torna las empresas más competitivas.

Pero innovar siguiendo las tres dimensiones de la sustentabilidad aún no es la regla. Según J. Barbieri et al. (2010) la inclusión de las dimensiones sociales y ambientales requiere nuevos instrumentos y modelos de gestión, que solo recientemente comenzaron a ser desarrollados con más intensidad y, ello no es tarea solo de las empresas que pretenden innovar. Las instituciones de enseñanza e investigación, los órganos gubernamentales, las instituciones de normalización, la organización de la sociedad civil, o sea, el sistema nacional de innovación también tiene un papel importante en esa problemática.

Por lo tanto, para que la sustentabilidad se incorpore efectivamente en el desarrollo de innovaciones, es fundamental que el sistema nacional de innovación esté movilizado para ello, debiendo contribuir juntamente con las organizaciones empresariales para la consecución de esa propuesta.

\section{FÚTBOL: INDUSTRIA, PLAYERS Y DESAFIOS}

El fútbol sufrió innúmeras transformaciones a lo largo de la historia. El éxito del fútbol profesional como espectáculo de masa estuvo íntimamente relacionado con su conversión en principal opción de ocio de las camadas "medias" y "bajas" de la población urbana. Habiéndose tornado un importante ingrediente de la industria cultural de consumo de masa.

El fútbol como modalidad deportiva tiene una grande fuerza aglutinadora sobre las colectividades, creando una poderosa identificación entre deporte y colectividades sociales en general. Se trata de una pasión capaz de mover multitudes y movilizar miles de personas. De acuerdo con la FIFA (...,2005), el fútbol es el deporte más practicado del mundo y posee aproximadamente 250 millones de practicantes.

Como parte integrante de la industria del entretenimiento, por los aspectos sociológicos que lo volvieron global, el surgimiento del mercado consumidor de espectáculos deportivos no es un evento histórico, pero un proceso más ligado a la popularización de su práctica. Según P. Bourdieu (1983), la popularidad de la práctica crea las bases para la consolidación de la industria del espectáculo, o sea, crea la demanda o el gusto de asistir a los partidos de fútbol, específicamente la figura del aficionado.

Para E. Ferreira (2010), a pesar del aficionado representar en la industria futbolística como consumidor final, una serie de consumidores intermedios (imprenta, lotería, patrocinadores y publicitarios) se utilizan del fútbol como recursos para ser vendidos a los consumidores finales, es decir, transforman campeonatos, juegos, clubes y jugadores en productos a ser vendidos a los aficionados. 
De acuerdo con M. Leoncini y M. Silva (2005) el mercado consumidor son aficionados que compran bienes y servicios para su consumo personal. Mercado intermediador de acuerdo con P. Kotler (1995), los clientes de ese mercado compran derechos de exploración y transmisión de partidos y servicios de marketing deportivo teniendo en vista "revenderlos" al mercado de consumo.

El marketing puede ser dividido en dos otros tipos de mercados: el Intermediador Industrial, para el cual las operaciones o actividades de marketing deportivo prestado por las organizaciones deportivas representan o producen una manera alternativa de realización de sus objetivos de marketing a través de la promoción, publicidad, exposición en la media y el Intermediador de Reventa, para el cual las operaciones o actividades prestadas por las organizaciones deportivas como venta de derechos de utilización de los campeonatos y de la marca del club vía transmisión de los partidos, vía lotería deportiva y vía venta de productos licenciados.

Además del mercado final (consumidores) y de los mercados intermedios (industrial y reventa) hay el mercado productor o mercado de jugadores, donde según A. Rezende (2004, p. 58) "se caracteriza como un mercado donde el "talento" en el fútbol es negociado a "peso de oro", un mercado extremamente activo.

En ese sentido, los dichos mercados forman la industria del fútbol, de acuerdo con la consultoría Deloitte Touche Tohmatsu Limited (2012) es mayor que el producto interno bruto (PIB) de 25 países, donde movimiento cerca de US\$ 500 billones anualmente, montante equivalente a la $17^{\mathrm{a}}$ economía del planeta. Para J. Brunoro y A. Afif (1997), los números envolviendo el fútbol demuestran con absoluta clareza que el fútbol se tornó un negocio de relevancia, por abarcar en la sociedad globalizada su potencialidad de facturación.

De acuerdo con el informe final del Plano de Modernización del Fútbol Brasilero de la Fundación Getúlio Vargas (2000), muestran que el fútbol es una actividad económica con efecto multiplicador, mayor que varios sectores tradicionales, contabilizando en Brasil: trescientos (300) mil empleos directos; treinta (30) millones de practicantes (formales y no formales); quinientos ochenta (580) mil participantes en trece (13) mil equipos que participan de juegos organizados (deporte formal); quinientos ochenta $(580)$ estadios con capacidad para abrigar más de cinco y medio $(5,5)$ millones de aficionados; cerca de quinientos (500) clubes profesionales disputando una media de noventa (90) partidas por ano; y en términos de fornecimiento anual de materiales y equipamientos deportivos, son cerca de nueve (9) millones de botas para fútbol y zapatillas para futsal, seis (6) millones de balones treinta y dos (32) millones de camisas.

De acuerdo con C. Silva y L. Campos Filho (2006), cerca de 1 millón de empleos pueden ser creados en diez años en Brasil con la profesionalización de la industria del fútbol. Esto se torna aún más imperativo ya que hay urgentes necesidades socioeconómicas de Brasil.

Las causas para este sub aprovechamiento están correlacionadas a la gestión tradicionales de las instituciones futbolísticas (clubes, ligas, federación y confederación) principal causa del fútbol brasilero no explorar totalmente su potencial económico y social.

Los clubes de fútbol en Brasil, según C. Perera et al. (2004) presentan sistemáticamente situación deficitaria, que resulta en endeudamiento bancario, incumplimiento fiscal y plan de seguridad, atrasos en las obligaciones laborales y en los sueldos de los jugadores. Además, para Aidar, Leoncini, y Oliveira (2000b) el descaso con el cliente-aficionado caracterizado por la violencia en los estadios, el exceso de negociación de los mejores jugadores para Europa, las maniobras 
políticas de dirigentes de federación cambiando reglas de acceso y descenso entre divisiones de los campeonatos estaduales y nacionales de fútbol.

Figura 2. Estructura de la red productiva en la industria del fútbol

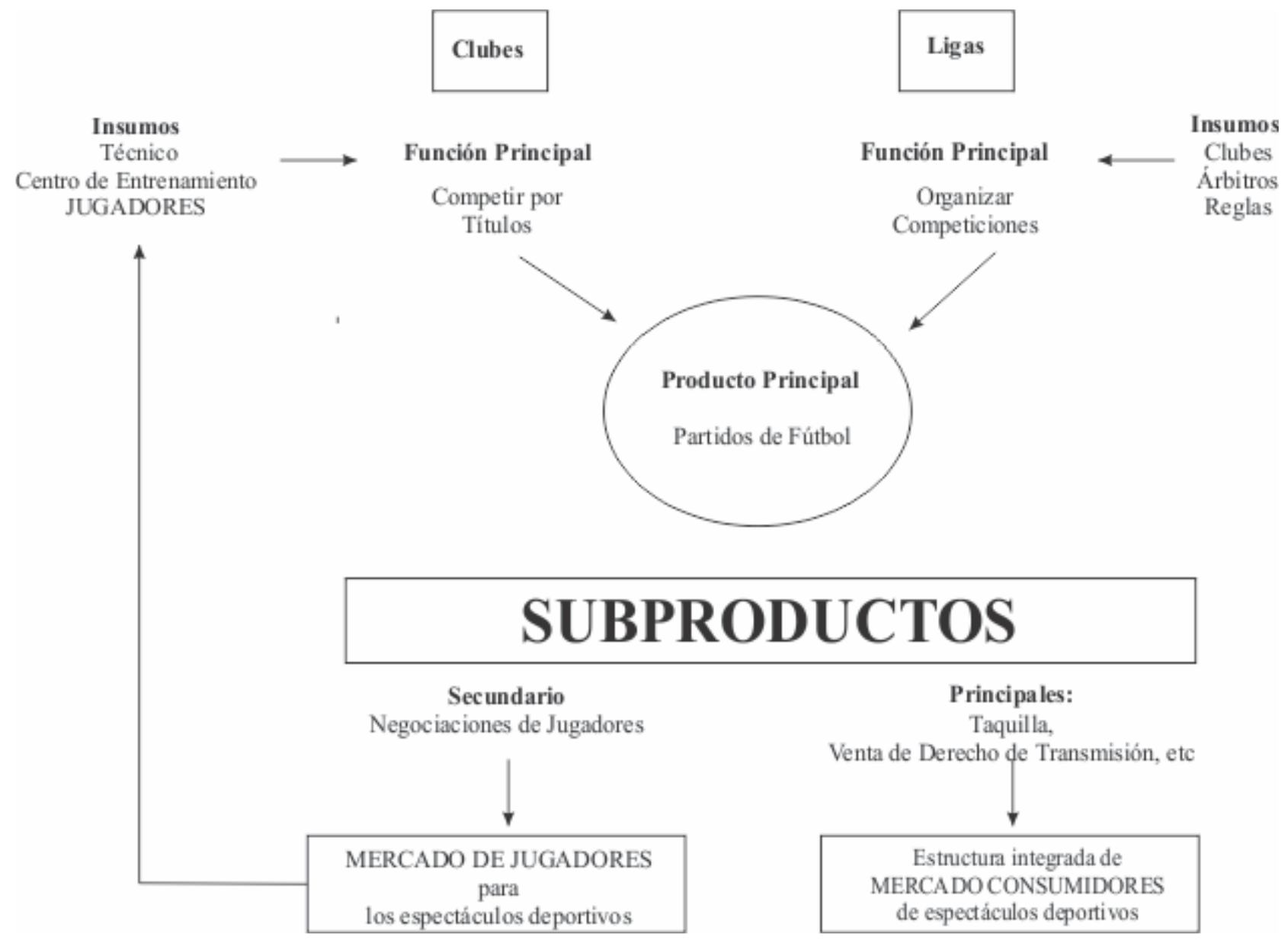

Fuente: M. Leoncini y M. Silva (2005).

Todas esas acciones representan políticas administrativas o posicionamientos estratégicos tenidos como equivocados y que, a la vez, dificultan el cambio de comando en el poder de clubes y federación y desvalorizan el potencial de generación de renta de esa industria (Leoncini; Silva, 2005).

Como ejemplo, el potencial financiero de los clubes brasileros, de acuerdo con M. Leoncini y M. Silva (1999), el deporte es un potencial de crecimiento y generación de empleos muy significativos debido a la cantidad de personas y organizaciones a él relacionadas.

Sin embargo, viene diseminando la necesidad de prácticas más transparentes, honestas y responsables en la gestión de los clubes de fútbol, de manera a repensar su estructura y su papel ante la sociedad, que demanda iniciativas en consonancia con los principios del desarrollo sustentable. 
La adopción de los principios y prácticas de la sustentabilidad empresarial pueden ayudar al proceso de reconstrucción administrativa y financiera de los clubes, sea por la reorganización de su estructura interna, sea por la atracción de inversiones motivada por esos cambios. Más que ello, la adopción de dichas prácticas contribuye para romper paradigmas y reconstruir la imagen de las agremiaciones; además de contribuir para la promoción social y preservación ambiental, añadiendo valor a todos sus stakeholders.

\section{LA SUSTENTABILIDAD EN EL FÚTBOL: CONTEXTO INGLÉS Y BRASILERO}

El concepto de sustentabilidad empresarial, de acuerdo con el Instituto Ethos (2003, p. 10) define como principal característica de la responsabilidad social corporativa:

[‥] la coherencia ética en las prácticas y relación con sus diversos públicos, contribuyendo para el desarrollo continuo de las personas, de las comunidades y de los relacionamientos entre sí y con el medio ambiente. Al añadir a sus competencias básicas la conducta ética y socialmente responsable, las empresas conquistan el respeto de las personas y de las comunidades atingidas por sus actividades, el compromiso de sus colaboradores y la preferencia de los consumidores.

Las organizaciones empresariales tienen un papel de destaque en la promoción del desarrollo sustentable.

Los clubes de fútbol, también son considerados organizaciones empresariales en Brasil, tras la ley $\mathrm{n}^{\circ} 9.615$ de 24 de marzo de 1998, también conocida como "Ley Pelé", que se tornó facultativa la transformación de los clubes en empresas. Luego, los clubes pueden tener un papel de relieve en la edificación y promoción de desarrollo sustentable, para la construcción de sociedades sustentables, como objetivo los indicadores de sustentabilidad empresarial, en la medida en que su industria mueve 500 billones de dólares anuales y posee 250 millones de practicantes en todo el mundo.

Además, los clubes juntamente con la Federación y Confederación, son organizaciones anclas de la red productiva futbolística, es decir, pueden influenciar cómo determinar posicionamientos de otros integrantes, sus clientes, aficionados, emisoras de televisión, empresas de marketing deportivo y licenciamientos, en consonancia con los principios del desarrollo sustentable, obteniendo un efecto multiplicador no solamente en la economía, como también en la promoción social y en la preservación ambiental.

Como fundamentación al expuesto anteriormente, de acuerdo con R. Spesoto (2008) se puede apuntar el fútbol inglés, considerado uno de los más profesionalizados del mundo. La liga inglesa con valor de mercado de $\mathrm{R} \$ 8,2$ billones, tiene como uno de sus principales players el Manchester United, considerado uno de los clubes de fútbol más ricos del mundo, con patrimonio evaluado en 2,3 billones de euros, considerado referencia en gestión futbolística. En la segunda mitad del siglo $\mathrm{XX}$, se tornó el grande nombre del fútbol frente a su modelo de gestión estratégica. En un primer momento, la estrategia contemplaba la contención de los costos y focalizaba la reducción de la principal fuente de gastos de los clubes, es decir, el gasto con sueldos y transferencias de jugadores.

El lucro surgió, pero, el desempeño en campo trajo la insatisfacción de aficionados y patrocinadores. Posteriormente, con el lanzamiento de acción en el mercado financiero, aumenta los lucros y el desempeño en campo finalmente puede ser notado, lo que torna el Manchester United un modelo de gestión estratégica eficaz. 
Para C. Pereira et al. (2004) en términos de objetivos estratégicos, este cambio significó alteración en la forma de ver el lucro, donde este pasa a ser visto como algo fundamental, y la estrategia de exploración de la marca del club su principal misión.

Además, en lo que se refiere a las dimensiones ambientales de la sustentabilidad empresarial, de acuerdo con el Sustainability in Sports (2014) el club posee las siguientes iniciativas:

- ISO14001: para el establecimiento de un sistema de gestión ambiental;

- Carbon Trust: patrón para la eficiencia energética y reducción de carbono;

- Reds Go Green: se centra en la eficiencia y reciclaje de residuos. Esta iniciativa ofrece lecciones sobre sustentabilidad para un número de escuelas locales y abarca áreas como mejores prácticas, gestión de residuos y reciclaje;

- Programa de eficiencia energética: incentiva los colaboradores para actuar como campeones de la energía y promocionar el uso eficiente de la energía en el trabajo;

- Aparcería con la WRAP: proyecto para incentivar los proveedores a adoptar prácticas ambientales en la eficiencia de los recursos;

- Creación de la reserva natural en Carrington, mantenida juntamente con la Cheshire Wildlife Trust.

En Brasil, siendo considerado un país con grande tradición en el fútbol, instrumento integrador de la sociedad brasilera y de la cultura nacional, su industria es aún considerada pequeña, en relación al PIB de Brasil. De acuerdo con R. Pedroso (2012) en relación al PIB de 2010, el fútbol, directa e indirectamente, fue responsable por $0,2 \%$ de todo lo que fue generado en el país. Caso la receta total hubiese atingido su potencial, ella representaría 1,1\% del PIB. En otras palabras, el fútbol brasilero generó R\$ 11 billones en 2010, pero la receta podría haber sido casi cinco veces más grande si el deporte tuviese una exploración más eficiente.

Las razones de ese sub aprovechamiento van desde la baja renta per capita del ciudadano brasilero hasta la gestión de los clubes y federación en Brasil, aunque con serios problemas administrativos y financieros, reflejo de gestiones no profesionalizadas y posicionamientos estratégicos considerados equivocados.

Para M. Soares (2007) mismo con los problemas del panorama supra dicho, se puede observar, mismo que tímidamente, cambios de posicionamientos, reformas y profesionalización administrativa de determinados clubes de fútbol en Brasil, para generación de valor para sus stakeholders, como también los integrantes de la red productiva del fútbol. Como fundamentación y ejemplo se puede señalar el Internacional de Porto Alegre.

El estadio Beira-Rio tiene como foco central la cuestión de la sustentabilidad. Las aguas provenientes de lluvias son reaprovechadas, tanto para mojar el campo y los jardines, como en la limpieza de áreas externas y en las descargas de los sanitarios. Además, el Beira Rio posee dispositivos con eficiencia energética, con una reducción de, como mínimo, 10\% del consumo anual del proyecto; área de colecta y acondicionamiento de residuos reciclables generados durante la operación del estadio y Plano de Prevención de Polución del Suelo y del Aire (eCycle, 2014). 
Pero, el ejemplo de más relieve de actuación empresarial en el fútbol en consonancia con los principios del desarrollo sustentable, direccionados por las metodologías de sustentabilidad empresarial para construcción de sociedades sustentables, es el Esporte Clube Corinthians Paulista, que reformuló su estructura administrativa, con foco en la generación de valor para sus stakeholders, a través de una reestructuración organizacional, tanto de sus cuadros dirigentes como en sus modos operantes.

De acuerdo con el informe de sustentabilidad de 2011 del Esporte Clube Corinthians Paulista (2012), desde 2010, participa con la Sociedade Esportiva Palmeiras, en aparcería con el Banco Cruzeiro do Sul, del proyecto Jugando con el Medio Ambiente proyecto, cuyo objetivo fue promocionar la responsabilidad socio ambiental por medio del fútbol y la carbo neutralización a través de la creación de una reserva ambiental en la ciudad de Salto de Pirapora/SP a través del plantío de árboles nativos de la Mata Atlántica. A finales de 2011, el número total llegó cerca de 50 mil nuevos esquejes plantados.

Sin embargo, la mayor contribución de ese club para la promoción del desarrollo sustentable es la publicación anual del Global Iniciative Report, principal herramienta de comunicación del desempeño social, ambiental y económico de las organizaciones. El E.C.Corinthians, desde 2008 es el único club de Brasil a realizar ese tipo de trabajo de acuerdo con las directrices de la Global Reporting Initiative GRI, entidad reconocida en el ámbito mundial que establece parámetros para la confección de este modelo de publicación, con la metodología más aceptada por las grandes organizaciones y entidades ligadas a la responsabilidad social empresarial.

El modelo de informe de la GRI es actualmente el más completo y mundialmente difundido. Su proceso de elaboración contribuye para el compromiso de las partes interesadas de la organización, la reflexión de los principales impactos, la definición de los indicadores y la comunicación con los públicos de interés (Krama, 2008). El conjunto de directrices e indicadores de la GRI proporciona la comparación, credibilidad, periodicidad y legitimidad de la información en la comunicación del desempeño social, ambiental y económico.

El Informe Sustentabilidad 2009 del club fue uno de los cinco finalistas del premio Abraza Mejor, Informe anual, ofrecido por la Asociación Brasilera de las Compañías Abiertas (Espacio RP, 2014).

Los ejemplos dichos: Manchester United, S. E. Palmeiras, Internacional y el E. C. Corinthians, son ejemplos de innovación en sustentabilidad, crean y añaden valores para los mercados que actúan, para sus stakeholders y otros integrantes de la red de valor. Además, sus respectivas actuaciones pueden ser consideradas nuevas en sus respectivas industrias.

La actuación de esos clubes, en consonancia con los principios del desarrollo sustentable, también puede ser considerada una innovación disruptiva de nuevo mercado. Los servicios son más accesibles y simple que pueden ser adquiridos y utilizados por una nueva faja demográfica, en este caso los aficionados, emisoras de televisión, empresas de marketing y licenciamiento no atendidos por organizaciones tradicionales de la industria del fútbol (Andrew; Sirkin, 2007).

Aunque deba considerarse positivo el posicionamiento tanto del club inglés como brasileros, es urgente la mayor inserción de los otros clubes de fútbol en Brasil la construcción de sociedades sustentables a través de la sustentabilidad empresarial, dado a las urgentes necesidades sociales, económicas y ambientales del país, donde el fútbol puede y debe contribuir. 
El cuadro a seguir sintetiza la importancia de la práctica de la sustentabilidad empresarial en los clubes de fútbol para el alcance de performance diferenciada que contemple todos sus stakeholders y demás integrantes de la red productiva.

\section{EL PROGRAMA ECO AFICIONADO}

El Programa Eco Aficionado, realizado por Manager Deportes en aparcería con la Federación Paulista de Fútbol con apoyo institucional de la Secretaría de Estado de Deporte, Entretenimiento y Juventud; Secretaría de Deportes, Entretenimiento y Recreación del Municipio de São Paulo y del Museo del Fútbol y patrocinio de la Tetra Pak, ocurrió entre los meses de enero a marzo de 2013, donde recogió las 17 ciudades-sedes del Campeonato Paulista Serie A1 y entrelazó los aficionados y clubes con acciones relacionadas a las dimensiones social, ambiental y económica del desarrollo sustentable.

El principal objetivo del Eco Aficionado es concienciar e incentivar al ciudadano aficionado a adoptar prácticas e iniciativas sustentables junto a la sociedad y a la comunidad donde reside, a través de su pasión por el fútbol. Se caracteriza como un trabajo de concienciación y participación de la sociedad paulista en las cuestiones de sustentabilidad a través del fútbol. El proyecto une los pilares social, ambiental y económico del desarrollo sustentable, por medio de acciones como plantío de bosques urbanos, colecta de residuos sólidos reciclables (aluminio, botellas plásticas 2 lt, cajas de leche y otros) y donación sociales (ropas, alimentos no perecederos y juguetes), con la finalidad de que el "Eco Aficionado" sea un agente transformador junto a su comunidad, una vez con la adhesión de todos los 20 clubes de la élite del campeonato paulista, son incentivados a tomar actitudes sustentables cuando transcurra el campeonato.

Por sus características generales, el Eco Aficionado está en consonancia con los objetivos de la sustentabilidad empresarial, pues se refiere a un modelo de negocio con base en valores éticos que incorporan las dimensiones social, ambiental y social de la sustentabilidad. También ayuda en la construcción y sustentación de ventaja competitiva pues crea para sus stakeholders valores que exceden el costo de crearlo.

Luego, el Eco Aficionado puede ser considerado una innovación sustentable pues introduce un nuevo modelo de negocio dentro de la red productiva del fútbol paulista y que trae beneficios económicos, sociales y ambientales. No se trata solamente de reducir impactos negativos, sino de avanzar en beneficios líquidos, donde los beneficios esperados contemplan las tres dimensiones del desarrollo sustentable. Además, podemos clasificarlo como una innovación en marketing, pues implementó un método de marketing con cambios en el posicionamiento del fútbol paulista para generación de valor que contemple resultados ambientales y sociales en su actividad.

El Eco Aficionado puede ser considerado también una innovación de ruptura de nuevo mercado. Los servicios son más accesibles y simple que pueden ser adquiridos y utilizados por una nueva faja demográfica, en este caso aficionados, emisoras de televisión, empresas de marketing y licenciamiento del estado de São Paulo que no eran atendidos por organizaciones tradicionales de la industria del fútbol (Andrew; Sirkin, 2007). 


\section{Figura 3. La ecuación del desempeño sustentable para los clubes de fútbol}

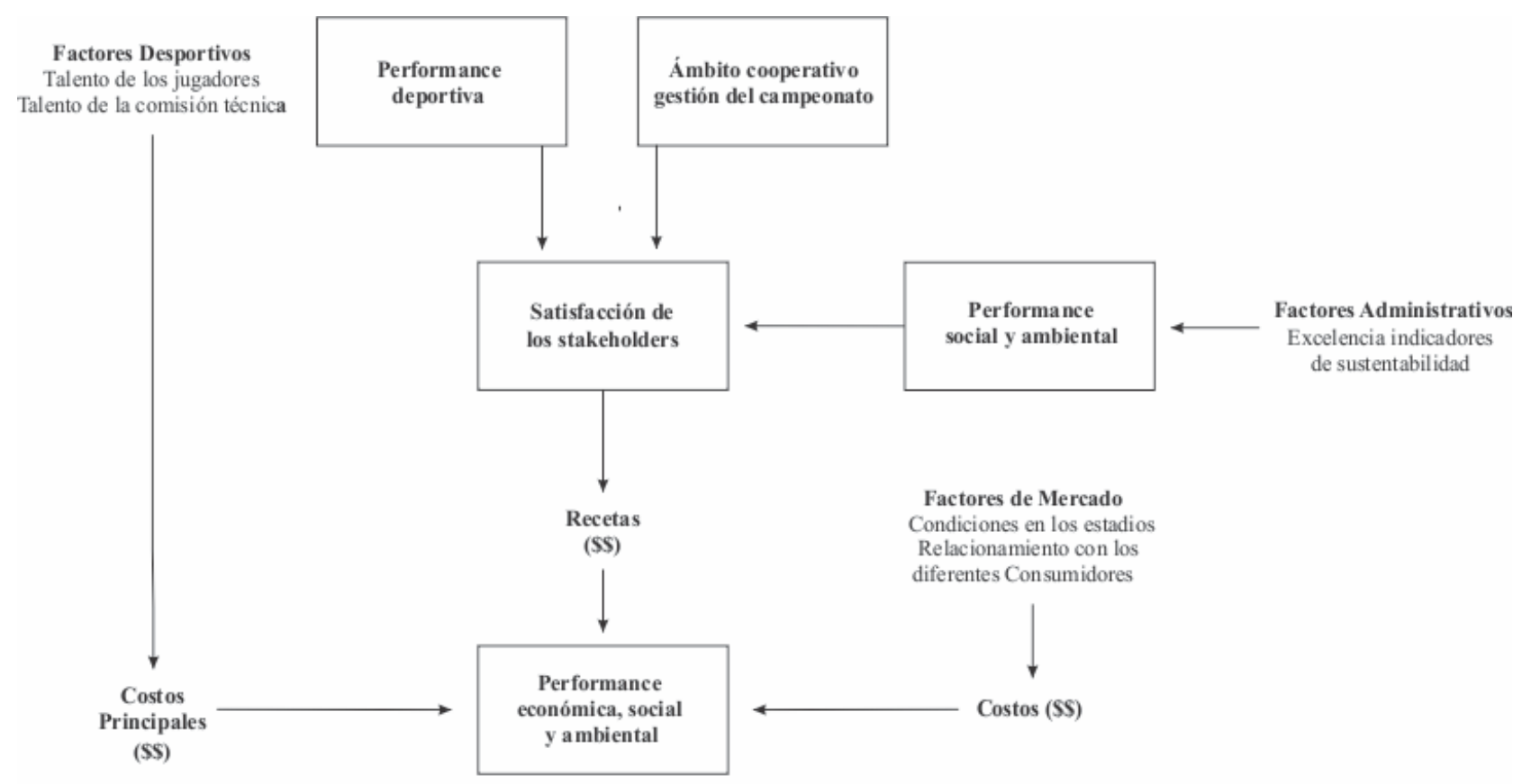

Fuente: Adaptado de M. Leoncini (2001).

De acuerdo con Lívio Giosa, Coordinador General del IRES - Instituto ADVB de Responsabilidad Socio ambiental, entidad que apoya el programa (Ciclo Vivo, 2013),

"Lo que estamos proponiendo es un trabajo de concienciación y participación proactiva de la sociedad paulista en las cuestiones de sustentabilidad a través de una grande pasión, que es el fútbol".

De acuerdo con Eduardo Eisler, Vice-presidente de Estrategia de Negocios de la Tetra Pak, patrocinadora del programa Eco Aficionado (Ciclo Vivo, 2013)

"Aliando la sustentabilidad al fútbol, esperamos reforzar el mensaje del reciclaje y de la colecta selectiva, y así movilizar a las personas por esta importante causa”.

De acuerdo con E. Sena (2013) a fin de materializar el envolvimiento de la sociedad en el proyecto, fueron propuestas actividades de interacción con los aficionados, siendo ellas:

- Plantación de bosques urbanos: La organización incentivó las municipalidades de las 17 ciudades representadas por los 20 equipos que disputaron el Campeonato Paulista a entregar un "Bosque Urbano", en áreas especialmente identificadas, o sea, un marco ambiental con un mínimo de 1.000 árboles. Cada municipio tuvo la responsabilidad de plantar árboles para iniciar su bosque junto a los aficionados. Además del trabajo de concienciación junto a los aficionados, esta acción tiene el objetivo de compensar el $\mathrm{CO}_{2}$ emitido para realización de la competición y dejar en cada ciudad un legado ambiental.

- Colecta de residuos sólidos reciclables: La organización creó un Eco Punto en cada estadio por partido durante las 19 rondas del primer turno del campeonato. Los aficionados fueron 
incentivados a participar de la colecta selectiva y destinar correctamente los residuos sólidos reciclables generados en casa y en el estadio. La entrega de residuos valdrá puntos para los aficionados, para los clubes y para las municipalidades, y el material será reciclado por medio de las cooperativas y recogedores de reciclables regionales.

- Donaciones sociales: La organización, juntamente con las municipalidades, creó un "Puesto de Colecta" en cada ciudad en un partido de las 19 rondas del primer turno del campeonato. Los aficionados, clubes y las municipalidades fueron incentivados a donar ropas, abrigos, alimento y/o juguetes para distribución a las instituciones y entidades de asistencia social locales.

- Fanáticos: Fueron premiados los 32 (treinta y dos) aficionados con mayor participación en los juegos del Campeonato Paulista en el primer turno. Estos aficionados deberán ficharse en el aplicativo "fanáticos" y señalar a cada ronda su ida al partido que compareció. Al final de la campaña deberá comprobar su presencia en los partidos declarados a través de la entrega a la organización de los tickets de cada partido. Los 32 aficionados que comprobadamente tengan mayor asiduidad en los partidos del primer turno participarán de una tarde de partidos festivos en uno de los estadios oficiales del Campeonato Paulista 2013, además de su participación en un torneo realizado en el estadio Pacaembu con los aficionados representando sus respectivos clubes. La participación podrá ser vía internet o a través de acción incentivando la adhesión de escuelas y empresas.

- Distribución de cuadernillos: En los Eco puntos hubo la distribución de cuadernillos educativas, con el objetivo de sensibilizar los aficionados sobre prácticas sustentables. En todas las ciudades-sedes del Campeonato Paulista de Fútbol, fueron distribuidas cerca de 100 mil ejemplares.

- Selección sustentable: Los aficionados participaron a través del aplicativo Eco Aficionado donde fueron premiados los 11 (once) aficionados que más acumularon puntos en las diversas acciones que puntuaron y para este programa formaron parte de la Selección Sustentable.

- Ecopa: El aficionado se ficha en los aplicativos "Eco Aficionado" y "Mi Estadio", y enseguida serán identificados los 6 (seis) aficionados que más acumularon puntos a través de las acciones individuales de cada uno de ellos. Los 16 aficionados que más puntúen en cada una de ellas, representarán su equipo en un torneo eliminatorio contra los demás clasificados en un estadio oficial del Campeonato Paulista.

- Escuela sustentable: Fue premiada la Institución de Enseñanza (fundamental, media o superior), compuesta por un equipo de como mínimo 3 (tres) personas y como máximo 10 (diez) personas con la ayuda de un Tutor (Educador de la Institución), que elaboraron un vídeo con acción sustentables, que futuramente generarán beneficios tangibles para su municipio, barrio o escuela.

- Aumento de la participación del aficionado en los estadios: La Federación Paulista de Fútbol, a través del Programa Eco Aficionado, lanzó promoción de ingresos, adquiridos en cambio por dos o más botellas plásticas de 2 lt vacías, para aumentar la presencia de aficionados en los partidos con poca media de público en el "Paulistão". La promoción tiene causa "sustentable". El material recogido fue entregue a las empresas de reciclaje de la 
región donde fue realizado el partido. La Federación Paulista de Fútbol repasó el valor de R\$ 10,00 (diez reales) para cada ingreso cambiado. El resultado puede ser observado a seguir:

- Santos x São Caetano (4 de abril, en el Pacaembu) - 9 mil disponibles para cambio, con 5.201 negociados;

- Atlético x Mogi (20 de marzo) - 3.000 ingresos disponibles, y 2.372 negociados;

- Oeste x Guarani - todos los 4 mil ingresos promocionales negociados;

- Mogi Mirim x Mirasol (24 de marzo) - 3.000 ingresos para cambio por botellas y 2.392 negociados;

- São Caetano x Mogi Mirim (31 de marzo, en São Caetano do Sul) - 3.000 ingresos y 627 negociados.

La participación de las municipalidades en el programa Eco Aficionado fue importante, no solamente para el fomento de la participación cívica de los aficionados en los estadios de sus respectivas ciudades, sino también, como un instrumento de fomento de políticas públicas municipales en consonancia con los principios del desarrollo sustentable para la construcción de la sustentabilidad urbana.

Como puede ser confirmada a través del artículo periodístico, de la Más Magazine (2013), donde matiza:

La Coordinadora de Comunicación de la Municipalidad está comprometida con el desarrollo de las acciones del Eco Aficionado. En una grande movilización, las unidades de la ciudad de Lins de las empresas SABESP y RENUKA DE BRASIL invitaron los más de 4.100 colaboradores a una práctica sustentable y cada vez más importante en los días de hoy: la separación y correcta destinación de residuos reciclables. Quien también participó de la acción fue la Casa de Cultura y Ciudadanía de Lins, dando secuencia al proyecto "Gestión de Residuos Sólidos" que consiste en concienciar a los niños a respecto del reciclaje. Cada institución fue premiada con 2 ingresos, cedidos por el Departamento de Marketing do CAL, para el partido de este sábado (02/03) entre Linense y Ponte Preta, que fueron sorteados entre los participantes del Eco Aficionado que entregaron los residuos en los puntos de colecta. La SABESP destinó el material para la COOPERSOL y también sorteó un kit de brindis entre sus participantes.

El alcalde de Lins Edgar de Souza, en entrevista al LR1 (2013) afirmó sobre el Programa Eco Aficionado:

"Esa feliz iniciativa va hacia una de las prioridades de nuestra administración, que es la sustentabilidad, la gestión del desarrollo respetando el medio ambiente. Tengo certeza de que la población de Lins irá corresponder”, dijo.

Dijo el presidente del club Linense, Rogério Camara, también en entrevista al LR1 (2013):

"Lins, a través del Clube Atlético Linense y de las instituciones aparceras, no podría estar fuera de ese proyecto. Nosotros iremos iniciar una grande movilización para que [...] podamos dar un show de civilidad y consciencia ambiental"

Además de la ciudad de Lins, la Municipalidad de Mogi Mirim apoyó el proyecto en su ciudad, como se puede ver en el artículo del Mogi Mirim Esporte Clube (2013): 
En la mañana del viernes, día 08, en la Estación Educación, fue lanzado oficialmente el Proyecto Eco Aficionado, en Mogi Mirim. En la ocasión, estuvieron presentes por la Municipalidad, el vice-alcalde, Gerson Rosi Junior, la directora de la Promoción Social, Beatriz Maretti Marangoni, el director de los Departamentos de Medio Ambiente y de Agricultura, Abastecimiento y Estradas Rurales (DAAER), Valdir Biazotto y la directora de Educación, Andréia Abbiati. También compareció al evento la asesora de Marketing del Mogi Mirim Esporte Clube, Mariela Braga. [...] El último domingo, día 06, el alcalde Gustavo Stupp llamó la atención de los aficionados, en el Estadio Romildo Vitor Gomes Ferreira, cuando entró en campo junto con el equipo del "Sapo" cargando un esqueje de árbol natural. La iniciativa ya formó parte del Proyecto Eco Aficionado. En ese momento, fueron donadas por la Municipalidad, a través del DAAER, 70 esquejes de árboles nativos. En este domingo, 10, cuando acontece el partido entre Mogi y Palmeiras, serán distribuidas más 100 esquejes, en el Estadio Romildo Vitor Gomes Ferrera, donados por la Municipalidad a través del DAAER, de esa vez, de árboles fructíferos. En la oportunidad serán instalados los Eco Puntos para la colecta de residuos. La entrega de residuos valdrá puntos para los aficionados, para el club y para la Municipalidad, siendo que el material será destinado al reciclaje por medio de las cooperativas y recogedores regionales.

Los resultados alcanzados por el Eco Aficionado, de acuerdo con el Envolverde Periodismo (2013) durante los meses de enero a marzo de 2013, donde recurrieron las 17 ciudades-sedes del Campeonato Paulista Serie A1, fueron:

- Más de 1 tonelada de residuos reciclables fueron colectados en los Eco Puntos instalados en los estadios;

- Distribución de 100 mil cuadernillos educativos;

- Fueron plantados 16.260 esquejes para la formación de bosques urbanos;

- Recaudación de 12.220 ítems en ropas y juguetes;

- 3 toneladas de alimentos no perecederos;

- 35 mil ítems de higiene y limpieza para distribución a entidades de asistencia social.

El municipio de Mogi Mirim fue el que presentó los mejores resultados, cumpliendo todas las acciones propuestas por el Programa. El alcalde Luís Gustavo Antunes Stupp fue homenajeado con el trofeo "Alcalde Sustentable".

En las palabras de Lívio Giosa, director ejecutivo del Programa Eco Aficionado, en entrevista al Envolverde Periodismo (2013) señala que:

Los resultados superaron nuestras expectativas, tanto por la participación activa de los aficionados como por el compromiso de las municipalidades, Secretarías de Deportes y Medio Ambiente. Se quedó claro y aprobado que el fútbol puede y debe cumplir un importante papel como formador de opinión para la sustentabilidad, incentivando actitudes que reflejan la nueva base de la consciencia ciudadana. Debemos, por tanto, hacer de eso una práctica continua, especialmente preparándonos para los grandes eventos deportivos

El cuadro a seguir sintetiza el posicionamiento del Eco Aficionado en la red productiva de fútbol con el valor entregue a sus stakeholders y demás integrantes de la red productiva. 


\section{CONCLUSIÓN}

A principios del siglo XXI fue marcado por la profunda necesidad de reforma del capitalismo, donde es necesario, no solamente la producción de riquezas, pero también la promoción social, especialmente para los más marginalizados del sistema económico, concomitantemente y la preservación ambiental. Ante las catástrofes ambientales y consecuentemente sociales presentes y previstas para hasta el fin de ese siglo es imperativo la emergencia de modelos de desarrollo que respondan de forma satisfactoria al presente desafío.

Estos desafíos fueron y continúan siendo tema de grandes investigaciones y discusiones multilaterales que se iniciaron con la publicación del Informe Meadows, pasando por la Conferencia de Estocolmo en 1972, publicación del Informe Brundtland en 1987, Rio 92, Rio +10 en Johanesburgo y más recientemente la Rio +20 . Aunque sus avances efectivos hayan sido cuestionables, la consolidación del concepto de sustentabilidad como el principal valor de una sociedad con las características necesarias para consolidar un sistema social justo, ambientalmente equilibrado y económicamente próspero por un largo período de tiempo, desarrollado bajo la luz de la gestión continuada, como un objetivo a ser alcanzado a través del desarrollo sustentable, responde a las necesidades del presente, sin comprometer el desarrollo de las generaciones futuras, con el objetivo de asegurar el equilibrio de las tres dimensiones del desarrollo sustentable (económica, social y ambiental) con un gobierno permanente, fue el grande legado de esas investigaciones y discusiones multilaterales.

Entre las herramientas de desarrollo sustentable, la sustentabilidad empresarial se presenta como una de las más importantes, en la medida en que las organizaciones empresariales son factores clave en el sistema capitalista y grandes responsables por los impactos ambientales decurrentes de sus actividades económicas y, además, su poder es substancialmente considerable. Luego, presupone actividades de recuperación de áreas degradadas, productos y servicios que contribuyan para la mejoría de la performance ambiental y social de los consumidores.

Además, las organizaciones empresariales y sus respectivas industrias, no deben solamente obtener excelencia en la instrumentalización para la ejecución de la sustentabilidad empresarial, pero también capilaridad social para sus actividades hacia la construcción de sociedades sustentables que impacten los ciudadanos con el objetivo de que los mismos sean agentes transformadores de la sociedad con base en las premisas del desarrollo sustentable.

En ese sentido, las organizaciones empresariales que actúan en la red productiva del fútbol (clubes, federación, confederación, empresas de comunicación, materiales y marketing deportivo), con un público practicante de aproximadamente 250 millones de practicantes, con una economía de 500 billones de dólares y cerca de 1 billón de espectadores, como fue la final del Mundial de Fútbol FIFA África del Sur 2010, poseen un papel importante en la reforma del modelo de desarrollo.

En Europa, donde la industria del fútbol es una de las más profesionalizadas del mundo, con resalte para Inglaterra, clubes como el Manchester United poseen no solamente resultados económicos diferenciados, sino que también el desempeño social y ambiental, donde se consigue entregar valor para las empresas, red productiva del fútbol y también a todos sus stakeholders.

En Brasil, aunque las necesidades económicas, sociales y ambientales sean más urgentes que las europeas en ese momento, los clubes de fútbol aún no presentan una serie de problemas financieros $\mathrm{y}$ administrativos, a través de posicionamientos estratégicos equivocados y gestiones no profesionalizadas. Como consecuencia al escenario dicho anteriormente hay una industria del fútbol 
no sub aprovechada, muy inferior a los resultados económicos, sociales y ambientales que podrían ser alcanzados si el mismo fuese profesionalizado como el fútbol europeo.

Sin embargo, acción como la del Internacional de Porto Alegre - Brasil, con el Estadio Beira Rio adecuado a los patrones ambientales, la Sociedade Esportiva Palmeiras en el programa Jugando por el Medio Ambiente y el Esporte Clube Corinthians Paulista que, además de contribuir con el proyecto, desde 2008 publica el GRI, principal herramienta de comunicación del desempeño social, ambiental y económico de las organizaciones; son fundamentaciones para la afirmación que es posible que los clubes de fútbol en Brasil contribuyan para el desarrollo sustentable del país.

El Eco Aficionado, programa con objetivo de concienciar e incentivar el ciudadano aficionado a adoptar prácticas e iniciativas sustentables junto a la sociedad y a la comunidad donde vive, a través de su pasión por el fútbol, objeto de estudio de ese artículo; es un intento de llevar, específicamente para la industria del fútbol paulista de la Serie A1 del año 2013, iniciativas que pudiesen generar valores para las organizaciones pertenecientes a esa industria, pero también todos stakeholders de las organizaciones participantes del proyecto, pues diferentemente de los clubes Internacional, Palmeiras y Corinthians, donde sus acciones generan valores solamente para sus aparceros, el Eco Aficionado genera para todos integrantes de la red de valor del fútbol paulista de la serie A1 en 2013.

Por ser un hecho inédito en el fútbol brasilero, se puede considerar el Eco Aficionado como una innovación en sustentabilidad, pues introduce un nuevo modelo de negocio dentro de la red productiva del fútbol en la provincia de São Paulo y que trae benefícios económicos, sociales y ambientales, comparados con alternativas pertinentes. El Eco Aficionado surge como una innovación de ruptura de nuevo mercado. Los servicios son más accesibles y sencillos que pueden ser adquiridos y utilizados por una nueva faja demográfica, en este caso aficionados, emisoras de televisión, empresas de marketing y licenciamiento del estado de São Paulo que no eran atendidos por organizaciones tradicionales de la industria del fútbol.

Los resultados logrados en su primera edición y la forma en el cual fue ejecutado permiten su intercambio tanto para otras modalidades deportivas como para otros países, pero, el grado de éxito del proyecto está directamente ligado a la capacidad de público, carisma que la modalidad deportiva ejerce sobre la sociedad y el grado de consciencia socio ambiental de la misma.

Por lo tanto el proyecto Eco Aficionado va hacia los esfuerzos promocionados por las organizaciones deportivas al añadir valores a sus respectivas marcas, construir y fundamentar ventaja competitiva, promocionar la inclusión social a través de donaciones sociales, preservación y promoción ambiental a través de la creación de bosques urbanos, colecta de residuos sólidos reciclables y el ejercicio de la educación ambiental en toda la sociedad a través de las escuelas sustentables, por tanto, acciones en consonancia con los principios sustentables y de los desafíos a ser superados en el siglo XXI. 


\section{Figura 4. Estructura de la red productiva en la industria del fútbol con el programa Eco Aficionado}

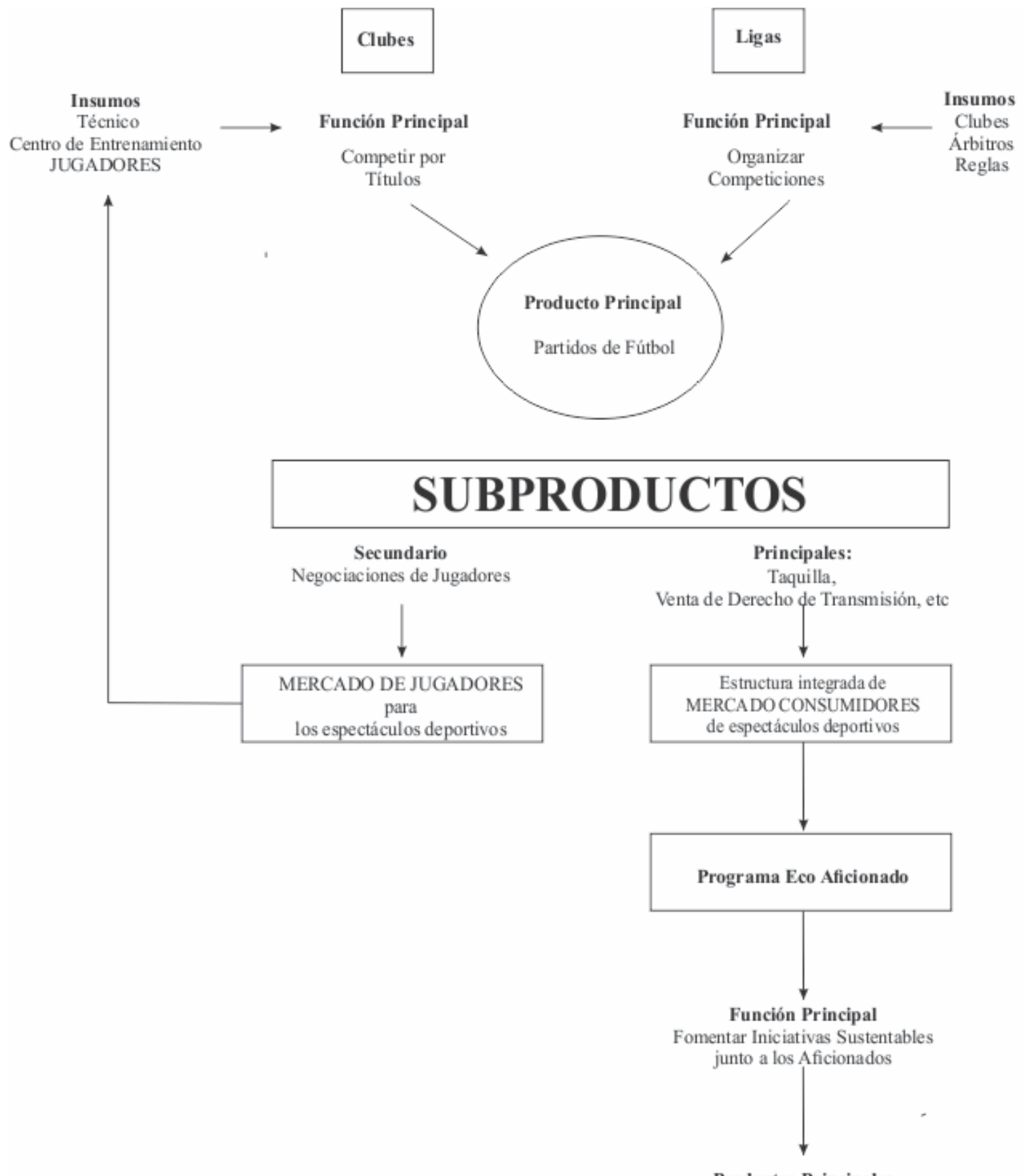

Educación Ambiental, Colecta de residuos sólidos reciclables, donaciones sociales, formación de bosques urbanos, aumento de público en los estadios. fomento de políticas públicas socio ambientales y valoración de la marca de los Clubes,

Fuente: Adaptado de M. Leoncini y M. Silva (2005). patrocinadores, federaciones y confederaciones.

Aunque el Eco Aficionado dé su contribución para el desarrollo del fútbol en Brasil, es necesario que los clubes de fútbol sean profesionales y con eso puedan explorar esa industria en el país de manera no solo optimizando las ganancias económicas, sino que tornándose también agentes transformadores de la sociedad brasilera, a través de trabajos relacionados a la promoción social, 
preservación ambiental, sobre todo en esa época histórica, donde nunca fue tan urgente una respuesta a los retos socio ambientales.

Como sugerencia para otras investigaciones se sugiere el estudio y/o análisis del proyecto "Jugando por el Medio Ambiente", los resultados al calor del desarrollo sustentable del Mundial FIFA Brasil 2014 y los modelos de gobierno corporativo de los grandes clubes del fútbol europeo.

\section{BIBLIOGRAFÍA}

AIDAR, A. C. K., LEONCINI, M. P. y OLIVEIRA, J. J. Estrutura integrada de mercados para as organizações de futebol - a economia do mercado futebolístico: a nova gestão do futebol. Rio de Janeiro: Editora FGV, 2000 a.

AIDAR, A. C. K., LEONCINI, M. P. y OLIVEIRA, J. J. Estrutura integrada de mercados para as organizações de futebol - a economia do mercado futebolístico: a nova gestão do futebol. Rio de Janeiro: Editora FGV, 2000 b.

ANDREW, J. y SIRKIN, H. L. Payback: a recompensa financeira da inovação. São Paulo: The Boston Consulting Group, 2007.

ARAÚJO, G. C., MORAIS, W. A. C. y MENDONÇA, P. S. M. M. O processo de adequação as normas internacionalmente reconhecidas em relação à sustentabilidade. In: Anais do Simpósio de Administração da Produção, Logística e Operações Internacionais, $\mathrm{n}^{\circ}$ 9, São Paulo, 2006. São Paulo: FGV-EAESP, 2006. p. 123-141.

BARBIERI, J. C. Desenvolvimento e meio ambiente: as estratégias de mudança da agenda 21. Petrópolis: Vozes, 1997.

BARBIERI, J. C., VASCONCELOS, I. F. G., ANDREASSI, T y VASCONCELOS, F. T. Innovation and Sustainability: New Models and Propositions. Revista de Administração de Empresas, 2010, vol. 50, n 2, p. 146-154.

BOURDIEU, P. Questões de sociologia. Rio de Janeiro: Marco Zero, 1983.

BRUNDTLAND, G. H. Nosso futuro comum: comissão mundial sobre meio ambiente $e$ desenvolvimento. Rio de Janeiro: Fundação Getúlio Vargas, 1991.

BRUNORO, J. C. y AFIF, A. Futebol 100\% profissional. São Paulo: Gente, 1997.

BRÜSEKE, F. J. O problema do desenvolvimento sustentável. In Cavalcanti, C. Desenvolvimento e natureza: estudos para uma sociedade sustentável. São Paulo: Cortez; Recife: Fundação Joaquim Nabuco, 1995. p. 30-67.

CAVALCANTI, C. (Coord.). Desenvolvimento e natureza: estudos para uma sociedade sustentável. São Paulo: Cortez, 1995.

CHRISTENSEN, C. M. The Innovator's Dilemma: When New Technologies Cause Great Firms to Fail. Boston: Harvard Business School Press, 1997. 
CHRISTENSEN, C. M. y RAYNOR, M. E. Innovator's Solution: Creating and Sustaining Successful. Boston: Harvard Business School Press, 2003.

CORAL, E. Modelo de planejamento estratégico para a sustentabilidade empresarial. Tese de Doutorado em Engenharia da Produção. Florianópolis: Universidade Federal de Santa Catarina, 2002.

CORDANI, U. G., MARCOVITCH, J. y SALATI, E. Avaliação das ações brasileiras após a Rio92. Estudos Avançados [on line], 1997, vol. 11, $\mathrm{n}^{\mathrm{o}}$ 29. Disponible en: $<$ http://www.scielo.br/scielo.php?script=sci arttext\&pid=S010340141997000100019\&lng=en\&nr $\underline{\mathrm{m}=\mathrm{iso}}>$. [Consulta: 10 enero 2014].

DAHL, A. L. The Big Picture: Comprehensive Approaches. In: Moldan, B. and Bilharz, S. Sustainability Indicators: Report of the Project on Indicators of Sustainable Development. Chichester: John Wiley \& Sons, 1997, p. 1-17.

FERREIRA, E. J. C. A utilização de técnicas de marketing esportivo como forma de fortalecimento da relação torcedor-clube: um estudo sobre o CRB. Monografia em Administração. Maceió: Universidade Federal de Alagoas, 2010.

FONSECA, J. J. S. Metodologia da pesquisa científica. Fortaleza: UEC, 2002.

Fundação Getúlio Vargas. Relatório final do plano de modernização do futebol brasileiro. Rio de Janeiro: Fundação Getúlio Vargas/Confederação Brasileira de Futebol, 2000.

GUIMARÃES, R. P. A assimetria dos interesses compartilhados: América Latina e a agenda global do meio ambiente. In: Leis, H. R. Ecologia e política mundial. Rio de janeiro: Vozes, 1991. p. 6884.

HOBSBAWN, E. A era dos extremos: o breve século XX: 1941-1991. São Paulo: Companhia das Letras, 1995.

HUSTED, B. W. y ALLEN, D. B. Toward a Model of Corporate Social Strategy Formulation. Washington: Academy of Management, 2001.

Instituto Ethos. Responsabilidade social das empresas: a contribuição das universidades. São Paulo: Peirópolis, 2003.

International Union for Conservation of Nature and Natural Resources, United Nations Environment Programme, World Wildlife Fund. World Conservation Strategy: Living Resource Conservation for Sustainable Development. Gland: IUCN/UNEP/WWF, 1980.

JACOBI, P. Dilemas socioambientais na gestão metropolitana: do risco a busca da sustentabilidade urbana. Política e Trabalho, 2006, n 25, p. 115-134.

KELLY, R. y MOLES, R. Towards Sustainable Development in the Mid-West Region of Ireland. Environmental Management and Health, 2000, vol. 11, n 5, p. 422-432.

KOTLER, P. Princípios de marketing. São Paulo: Atlas, 1995. 
KRAMA, M. R. Análise dos indicadores de desenvolvimento sustentável no Brasil usando a ferramenta painel de sustentabilidade. Dissertação de Mestrado em Engenharia de Produção e Sistemas. Curitiba: Pontifícia Universidade Católica do Paraná, 2008.

LAGO, A. A. C. Estocolmo, Rio, Joanesburgo: o Brasil e as três conferências ambientais das Nações Unidas. Brasília, DF: Fundação Alexandre de Gusmão, 2006.

LEONCINI, M. P. Entendendo o negócio do futebol: um estudo sobre a transformação do modelo de gestão estratégico nos clubes de futebol. Tese de Doutorado em Engenharia de Produção. São Paulo: Universidade de São Paulo, 2001.

LEONCINI, M. P. y SILVA, M. T. Entendendo o futebol como negócio: um estudo exploratório. Gestão e produção, 2005, vol. 12. n 1, p. 11-23.

LEONCINI, M. P. y SILVA, M. T. Futebol como fábrica de serviços. In: Encontro Nacional de Engenharia de Produção, n 18, Niterói, 1999. Niterói: UFF. p. 23-46.

LIMA, G. F. C. O debate da sustentabilidade na sociedade insustentável. Revista Politica e Trabalho, 1997, vol. 21, nº 13, p. 201-222.

MACHADO FILHO, C. A. P. y ZYLBERSZTAJN, D. A empresa socialmente responsável: o debate e as implicações. RAUSP, 2004, vol. 39, n 3, p. 242-254.

MIKHAILOVA, I. Sustentabilidade: evolução dos conceitos teóricos e os problemas da mensuração prática. Revista Economia e Desenvolvimento [on line], 2004, $\mathrm{n}^{\circ}$ 16. Disponible en:

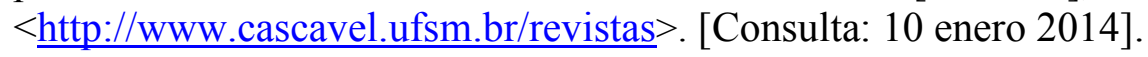

MOTA, J. A., GAZONI, J. L., REGANHAN, J. M., SILVEIRA, M. T. y GÓES, G. S. Trajetória da governança ambiental. Boletin Regional e Urbano, 2008, $\mathrm{n}^{\circ} 1$.

NIDUMOLU, R., PRAHALAD, C. K. y RANGASWAMI, M. R. Why Sustainability is Now the Key Driver of Innovation? Harvard Business Review, 2009, vol. 87, nº 9, p. 56-64.

Organisation for Economic Cooperation and Development. The Oslo Manual: the Measurement of Scientific and Technical Activities. Paris: OECD, 1997.

PASSOS, P. N. C. A conferência de Estocolmo como ponto de partida para a proteção internacional do meio ambiente. Revista Direitos Fundamentais e Democracia, 2009, vol. 6, p. 305-329.

PEDROSO, R. Para FGV, receita do futebol pode chegar a 1,1\% do PIB. Valor Econômico, 11 janeiro 2012, p. 26. Negócios.

PEREIRA, C. A., REZENDE, A. J., CORRAR, L. J., y LIMA, E. M. A gestão estratégica de clubes de futebol: uma análise da correlação entre performance esportiva e resultado operacional. In: Congresso USP de Controladoria e Contabilidade, $\mathrm{n}^{\circ}$ 4, São Paulo, 2004. São Paulo: USP, 2004. p. 22-37.

PORTER, M. E. Competitive Advantage: Creating and Sustaining Superior Performance. New York: Free Press Collier Macmillan, 1985. 
PORTER, M. E. y VAN DER LINDE, C. Green and Competitive: Ending the Stalemate. Harvard Business Review, 1995, vol. 73, n 5, p. 120-134.

RATTNER, H. y VEIGA, J. E. Desenvolvimento sustentável [on line]. São Paulo: 2014. Disponible en: $<$ http://www.economiabr.net/>. [Consulta: 14 noviembre 2014].

REZENDE, A. J. Estudo sobre as decisões identificadas na gestão de contratos de jogadores de futebol: o caso do clube Atlético Paranaense. Dissertação de Mestrado em Ciências Contábeis. São Paulo: Universidade de São Paulo, 2004.

SACHS, I. Ecodesenvolvimento: crescer sem destruir. São Paulo: Vértice, 1986.

SACHS, I. Estratégias de transição para o século XXI: desenvolvimento e meio ambiente. São Paulo: Studio Nobel, 1993.

SBARAINI, J. Inovação em processos: propostas de como gerar um funil adequado para projetos de inovação em processos. Campo Limpo Paulista: FACAMP, 2013.

SCHUMPETER, J. Teoria do desenvolvimento econômico. São Paulo: Nova Cultural, 1988.

SENA, E. Lançado o Programa Ecotorcedor no Campeonato Paulista de Futebol [on line]. São Paulo: 2013. Disponible en: <http://atitudesustentavel.com.br/ecocardiograma/>. [Consulta: 14 noviembre 2014].

SILVA, C. V. G. F. y CAMPOS FILHO, L. A. N. Gestão de clubes de futebol brasileiros: fontes alternativas de receita. Revista Eletrônica Sistemas \& Gestão, 2006, vol. 1, nº 3, p. 195-209.

SOARES, M. L. A miopia do marketing esportivo dos clubes de futebol no Brasil: proposta de um modelo de gestão de marketing esportivo para os clubes brasileiros. Tese de Doutorado em Administração. São Paulo: Universidade de São Paulo, 2007.

SPESSOTO, R. E. N. Futebol profissional e administração profissional: da prática amadorística à gestão competitiva. Dissertação de Mestrado em Educação Física. Brasília, DF: Universidade de Brasília, 2008.

STROBEL, J. S. Modelo para mensuração da sustentabilidade corporativa através de indicadores. Dissertação de Mestrado em Engenharia Ambiental. Florianópolis: Universidade Federal de Santa Catarina, 2005.

Sustainability in Sports. Case studies: Manchester United [on line]. Manchester: 2014. Available from: $\quad<$ http://www.sustainabilityinsport.com/case-studies/manchester-united $>$. [Consulta: 14 noviembre 2014].

TIDD, J., BESSANT, J. y PAVITT, K. Gestão da inovação. Porto Alegre: Bookman, 2008.

YOUNG, C. E. F. y LUSTOSA, M. C. J. Meio Ambiente e competitividade na indústria brasileira. Revista de Economia Contemporânea, 2001, vol. 5, p. 231-259. 
ZUCATTO, L. C. y PINHEIRO, I. A. Análise descritivo-analítica do uso combinado de ferramentas de gestão da inovação sob as abordagens da inovação disruptiva e da estratégia do oceano azul. In: Simpósio de Gestão da Inovação Tecnológica, n 34, Brasília, 2008. Brasília, DF: ANPAD, 2008. p. 1-16.

\section{RECURSOS ELECTRÓNICOS}

BRASIL. Lei $n^{\circ}$. 10.973, de 02 de dezembro de 2004 [on line]. Dispõe sobre incentivos à inovação e à pesquisa científica e tecnológica no ambiente produtivo e dá outras providências. Brasília, DF:

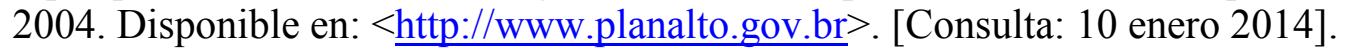

CICLO VIVO. Programa interativo promove a sustentabilidade no Campeonato Paulista de Futebol [on line]. São Paulo: 2014. Disponible en: $<$ http://ciclovivo.com.br/noticia/programa-interativopromove-a-sustentabilidade-no-campeonato-paulista-de-futebol>. [Consulta: 10 noviembre 2014].

Comitê de Qualidade da Gestão Pública [on line]. Declaração de Johanesburgo sobre desenvolvimento sustentável. $2002 . \quad$ Disponible en:

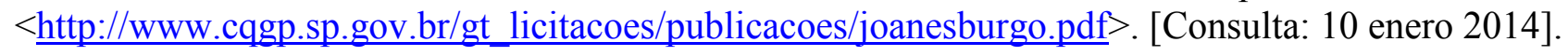

Conferência das Nações Unidas sobre o Desenvolvimento Sustentável: do Rio à Rio +20 [on line]. 2012. Disponible en: $<$ http://www.onu.org.br/rio20/tema/rio20/>. [Consulta: 10 enero 2014].

Deloitte Touche Tohmatsu Limited [on line]. Foreword. London: 2012. Available from: $<$ http://www.deloitte.com/assets/DcomUnitedKingdom/Local\%20Assets/Documents/Industries/Spo rts\%20Business\%20Group/uk-sbg-annual-football-finance-review-2012-foreword.pdf $>$.

[Consulta: 13 noviembre 2014].

eCycle. Atitude: Grandes times brasileiros vestem a camisa da sustentabilidade com projetos voltados para o meio ambiente [on line]. São Paulo: 2014. Disponible en: $<\underline{\text { http://www.ecycle.com.br/component/content/article/35-atitude/710-grandes-times-brasileiros- }}$ vestem-a-camisa-da-sustentabilidade-com-projetos-voltados-para-o-meio-ambiente-.html >.

[Consulta: 14 noviembre 2014].

Envolverde Jornalismo. Eco torcedor arrecada mais de 1 tonelada de resíduos recicláveis no paulistão 2013. [on line]. Lins: 2014. Disponible en: $<$ http://envolverde.com.br/noticias/ecotorcedor-arrecada-mais-de-1-tonelada-de-residuosreciclaveis-no-paulistao-2013/>. [Consulta: 13 noviembre 2014].

Espaço RP. Sustentabilidade e esporte no Brasil [on line]. Bauru: 2014. Disponible en:

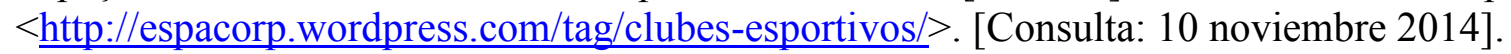

Esporte Clube Corinthians Paulista. Relatório de Sustentabilidade 2011 [on line]. São Paulo: 2012. Disponible en: <http://www.corinthians.com.br/upload/site/sccp-rs-2011-por.pdf $>$. [Consulta: 14 noviembre 2014].

FIFA faz censo sobre futebol no mundo. [on line]. São Paulo: 2014. Disponible en: $<$ www.estadao.com.br/esportes/noticias/2001/abr/03/158.htm $>$. [Consulta: 14 noviembre 2014]. 
Instituto Brasileiro do Meio Ambiente e dos Recursos Naturais Renováveis [on line]. História. 2009. Disponible en: < http://www.ibama.gov.br/am/institucional/historia.htm $>$. [Consulta: 9 enero 2014].

LR1. Sustentabilidade: Lins adere ao Projeto Eco torcedor [on line]. Lins: 2014. Disponible en: $<$ http://www.lr1.com.br/index.php?pagina=noticia\&categoria $=$ \&noticia $=39665>$. $\quad$ [Consulta: 13 noviembre 2014].

Mais Magazine. Eco Torcedor [on line]. Lins: 2013. Disponible en:

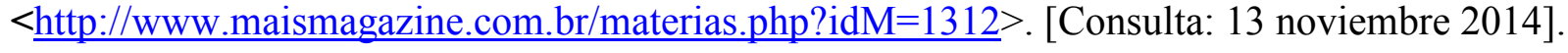

Mogi Mirim Esporte Clube. Eco Torcedor é lançado oficialmente [on line]. Mogi Mirim: 2013. Disponible en: $<\underline{\text { http://www.mogimirim.com.br/?p=1240> }}$. [Consulta 13 noviembre 2014].

Serviço Brasileiro de Apoio a Micro e Pequena Empresa [on line]. O que é inovação. Disponible en: $<$ http://www.facadiferente.sebrae.com.br/2009/03/11/o-que-e-inovacao/>. [Consulta: 9 enero 2014].

União Européia [on line]. Livro verde: Promover um quadro europeu para responsabilidade social das empresas. Bruxelas: 2001. Disponible en: $<\underline{\mathrm{http}}$ ://www.europa.eu.int/pol/sócio/index_pt.htm>. [Consulta: 10 enero 2014].

C Copyright Geraldo José Ferraresi de Araujo y Luiz Felipe Scaranti Navarro, 2015.

C Copyright GeoGraphos, 2015.

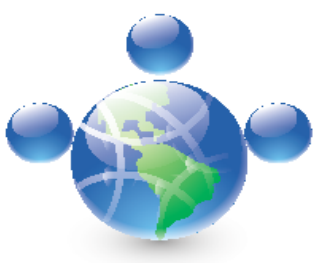

